\title{
Evolution of bilaterian central nervous systems: a single origin?
}

\author{
Linda Z Holland ${ }^{1 *}$, João E Carvalho ${ }^{2}$, Hector Escriva ${ }^{3}$, Vincent Laudet ${ }^{4}$, Michael Schubert ${ }^{2}$, Sebastian M Shimeld ${ }^{5}$ \\ and Jr-Kai $Y u^{6}$
}

\begin{abstract}
The question of whether the ancestral bilaterian had a central nervous system (CNS) or a diffuse ectodermal nervous system has been hotly debated. Considerable evidence supports the theory that a CNS evolved just once. However, an alternative view proposes that the chordate CNS evolved from the ectodermal nerve net of a hemichordate-like ancestral deuterostome, implying independent evolution of the CNS in chordates and protostomes. To specify morphological divisions along the anterior/posterior axis, this ancestor used gene networks homologous to those patterning three organizing centers in the vertebrate brain: the anterior neural ridge, the zona limitans intrathalamica and the isthmic organizer, and subsequent evolution of the vertebrate brain involved elaboration of these ancestral signaling centers; however, all or part of these signaling centers were lost from the CNS of invertebrate chordates. The present review analyzes the evidence for and against these theories. The bulk of the evidence indicates that a CNS evolved just once - in the ancestral bilaterian. Importantly, in both protostomes and deuterostomes, the CNS represents a portion of a generally neurogenic ectoderm that is internalized and receives and integrates inputs from sensory cells in the remainder of the ectoderm. The expression patterns of genes involved in medio/lateral (dorso/ventral) patterning of the CNS are similar in protostomes and chordates; however, these genes are not similarly expressed in the ectoderm outside the CNS. Thus, their expression is a better criterion for CNS homologs than the expression of anterior/posterior patterning genes, many of which (for example, Hox genes) are similarly expressed both in the CNS and in the remainder of the ectoderm in many bilaterians. The evidence leaves hemichordates in an ambiguous position - either CNS centralization was lost to some extent at the base of the hemichordates, or even earlier, at the base of the hemichordates + echinoderms, or one of the two hemichordate nerve cords is homologous to the CNS of protostomes and chordates. In any event, the presence of part of the genetic machinery for the anterior neural ridge, the zona limitans intrathalamica and the isthmic organizer in invertebrate chordates together with similar morphology indicates that these organizers were present, at least in part, at the base of the chordates and were probably elaborated upon in the vertebrate lineage.
\end{abstract}

Keywords: Central nervous system evolution, Hemichordate, Urbilaterian, Amphioxus, Tunicate, Vertebrate brain, Nerve cord

\section{Review Introduction}

There is general agreement that the relatively complex central nervous system (CNS) characterizing most higher metazoan animals can be traced back through evolution to a nerve net in a cnidarian-like ancestor.

\footnotetext{
*Correspondence: Izholland@ucsd.edu

${ }^{1}$ Marine Biology Research Division, Scripps Institution of Oceanography, University of California at San Diego, La Jolla, CA 92093-0202, USA Full list of author information is available at the end of the article
}

However, it is highly controversial whether the nervous system of the next evolutionary stage (the urbilaterian) still consisted solely of a nerve net or included a CNS. If the urbilaterian had only a nerve net, then the CNSs of protostomes and deuterostomes likely evolved independently. In contrast, the view that the urbilaterian had a CNS is consistent with the view that the CNSs of all metazoans are homologous. At present, opinion is still divided, with the majority advocating a single evolutionary origin for the CNS [1-8] and the minority favoring an urbilaterian with a nerve net $[9,10]$.

\section{Biomed Central}


This controversy about CNS evolution is intimately related to issues of homology, and it is useful to outline current thinking about homology at the outset. It is important not to conflate the concepts and recognition criteria for homology. There are currently three concepts underlying homology - biological [11], taxic/cladistic [12,13] and historical [14-16]. What matters for the last, which is the most familiar and most germane for the nervous system controversy, is the historical continuity of descent from a common ancestor. The historical concept requires one to be explicit about what is being compared [17]; for example, bird wings and bat wings are homologous as vertebrate forelimbs, but not as wings. Importantly, historical homologies can become very different through divergence. The three chief criteria for recognizing homology are relative position to other body parts, special quality, and transitional stages [18]. A developmental criterion, introduced by Haeckel [19], proved difficult to apply and has been largely submerged into the previous three criteria. Importantly, there are differing views concerning the hierarchical distribution of homology across levels of biological organization. In the view of Striedter and Northcutt, homology at one level (say behavior) does not necessarily connote homology at another (say morphology) [20]. In contrast, Wagner argued that structures descended from a common ancestor are homologous even if they have diverged and have no clear morphological similarity [16]. The problems raised by the hierarchical nature of homology have been heightened by the discovery of developmental gene conservation [21] and are especially noticeable in the discussion of CNS evolution.

In the past 20 years, it has been found that developmental genes and core signaling pathways are typically conserved across phyla and that gene expression patterns during development can often be used as characters for inferring homologies. Thus, although the majority view had been that the urbilaterian had a nerve net, the balance was tipped towards an urbilaterian with a CNS by the discovery that bone morphogenic protein $(B M P) /$ decapentaplegic genes were expressed dorsally in Drosophila and ventrally in vertebrates with the BMP antagonists chordin/short gastrulation expressed on the opposite side [22] (Figure 1). In this view, which is consistent with the CNSs of all higher metazoans being homologous, a dorso/ventral (D/V) inversion occurred either in basal protostomes or in the deuterostome lineage $[3,5,23]$. However, in the last 10 years, studies of gene expression and function in an enteropneust (acorn worm; phylum Hemichordata) have been interpreted as evidence that the ancestral deuterostome and, by extension, the urbilaterian had a nerve net and no CNS $[9,24,25]$. Thus, while a CNS would have arisen close to the base of the protostomes, the evolution of a CNS in deuterostomes did not occur until the base of the chordates. In the present review, we examine the detailed
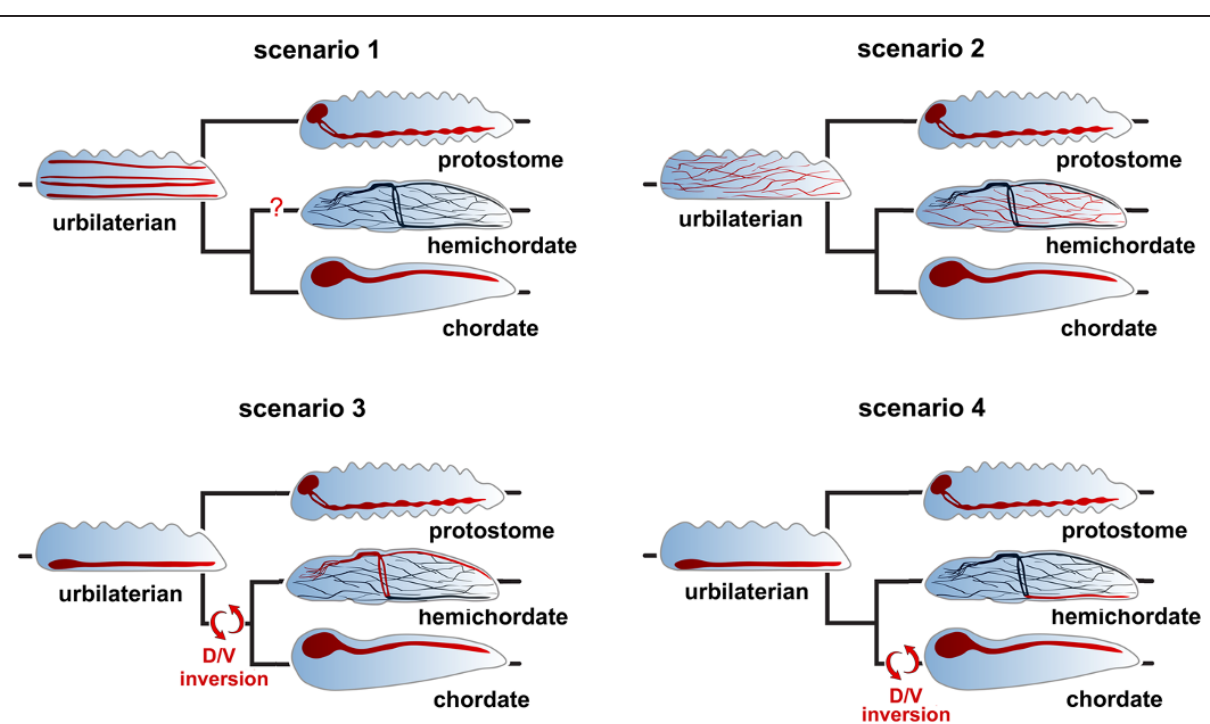

Figure 1 Four scenarios for evolution of central nervous systems in bilaterians. In scenario 1, the urbilaterian had multiple nerve cords, one of which evolved into the dorsal central nervous system (CNS) of chordates, while another nerve cord evolved into the ventral CNS of protostomes. In scenario 2, the CNSs of protostomes and deuterostomes evolved independently from an ectodermal nerve net in the bilaterian ancestor. In scenario 3, the chordate and protostome nerve cords evolved from a ventral nerve cord in the urbilaterian ancestor. A dorso/ventral (DN) inversion occurred at the base of the deuterostomes; the dorsal nerve cord of hemichordates is thus homologous to the chordate CNS and to the protostome ventral nerve cord. In scenario 4, the protostome and chordate nerve cords evolved from the CNS of an urbilaterian ancestor, but a DN inversion occurred at the base of the chordates. Thus, the ventral nerve cord of a hemichordate is homologous to the chordate and protostome CNSs. Scenarios after [1,3,7,23,26-29]. 
evidence on both sides of the controversy and evaluate its interpretations. We conclude that a stronger case can be made for the initial appearance of the CNS at the level of the urbilaterian than for independent evolution of the CNS in more than one line of metazoan descent.

\section{Reconstructing the ancestral bilaterian}

Although several features of the ancestral bilaterian in addition to the presence or absence of a CNS are widely debated, a range of molecular, developmental and comparative morphological evidence indicates that this animal was bilaterally symmetrical, with distinct anterior and posterior ends, dorsal and ventral surfaces, and left and right sides. It almost certainly had defined muscle, derived from mesoderm, allowing active locomotion and a gut with either a single opening or a separate mouth and anus [30]. Whether or not this animal had a CNS, an ectodermal nerve net or some combination of the two has been hotly debated (reviewed in [31]) (Figure 1).

One difficulty in deciding whether the ancestral bilaterian had a CNS is that the ectoderm in bilaterians is broadly neurogenic. Therefore, the distinction between the CNS and the remainder of the relatively neurogenic ectoderm is not always clear-cut. In chordates, arthropods and annelids, the distinction is most clear as there is a fully internalized concentration of neurons, axons and supporting cells along the anterior/posterior (A/P) axis (that is, a CNS) that integrates information from sensory cells both associated with the CNS (for example, eyes) and with other portions of the ectoderm and coordinates behavior. Importantly, the CNS in these organisms has an anterior concentration of discrete neural centers or "brain", which coordinates sensory inputs and responses. At the other extreme are "diffuse ectodermal nerve nets" such as in cnidarians. However, such nerve nets are not uniform; specific types of neurons may be regionally localized [32]. An additional problem in understanding the evolution of CNSs comes with the Ambulacraria (echinoderms and hemichordates), as they have both ectodermal nerve nets and nerve cords. It is controversial whether echinoderm and/or hemichordate nerve cords, neither of which has a concentration of neurons that could be termed a brain, and the CNS of chordates have a common evolutionary origin [33,34]. Here we will use the term CNS for a nervous system that is derived from ectoderm, includes both axons and neurons and is specialized along the $\mathrm{A} / \mathrm{P}$ axis with an anterior concentration of neural centers (brain), and the term "nerve cord" more broadly to include axonal tracts with few or no neurons and lacking a discrete brain. The diversity of animal nervous systems and paucity of data from some species may blur this distinction on occasion; however, we will be explicit in such instances.

\section{What is the evidence for a CNS in the ancestral bilaterian?}

It is generally agreed that bilaterians evolved from radially or bi-radially symmetrical animals, comparable in some ways to modern cnidarians. Adult cnidarians have an ectodermal nerve net with a concentration of neurons around the single gut opening (Figure 2). Therefore, if the ancestral bilaterian had already evolved a CNS, it would presumably have arisen as a concentration or amplification of neurons along one side of this nerve net, perhaps together with a reduction in numbers of neurons elsewhere in the ectoderm.

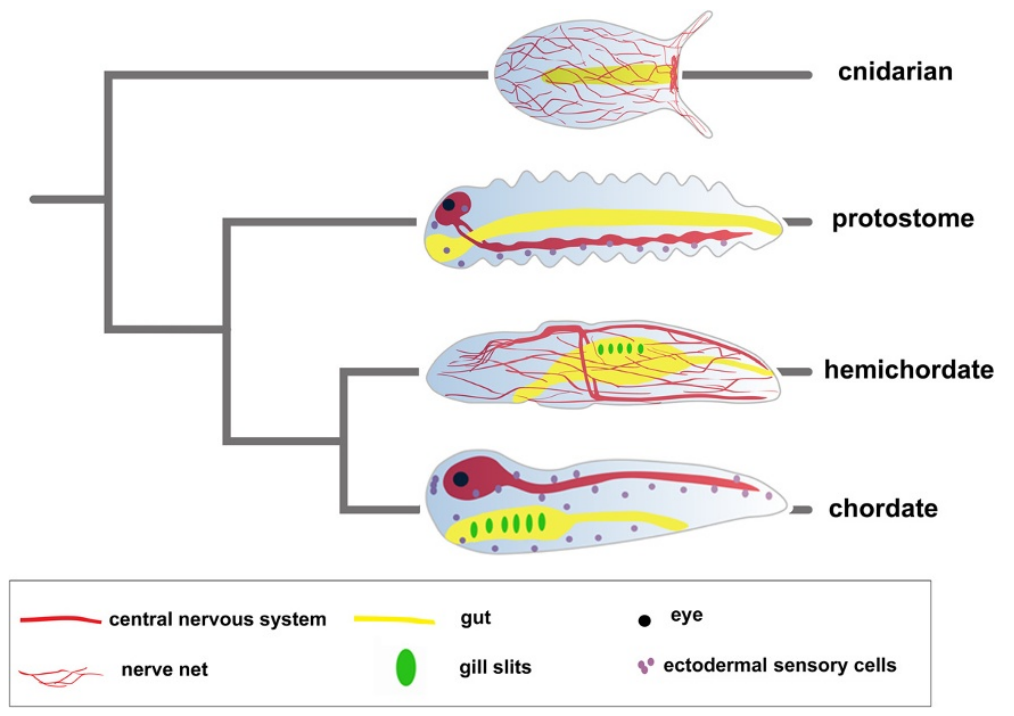

Figure 2 Comparison of metazoan body plans. A typical cnidarian polyp, a generalized protostome, hemichordate and chordate and their phylogenetic relations are shown. Special attention is given to nervous systems and neural structures of the respective animals. 
Unfortunately, no extant animal is a good stand-in for this ancestral bilaterian. Extant animals that are thought to have diverged from the bilaterian lineage before it radiated into the protostomes (Ecdysozoa and Lophotrochozoa) and the deuterostomes do not show an intermediate condition between a nerve net and a CNS (Figure 2). The best candidates for such early bilaterian offshoots are the acoel and nemertodermatid flatworms, and the xenoturbellids, which in some studies have been placed basal to the deuterostomes plus protostomes but in others are placed basal in the deuterostome lineage $[35,36]$. Acoels have a concentration of neurons, or a "brain", anteriorly with up to six tracts of axons extending posteriorly [37]. In contrast, xenoturbellids have an intraepithelial nerve net that lacks aggregations of neurons or axonal tracts [38]. As a result of the lack of a clear intermediate, scenarios for evolution of CNSs are necessarily based on similarities in gene expression and neuroanatomy in the two main lineages of bilaterians: protostomes (Ecdysozoa plus Lophotrochozoa) and deuterostomes (Figure 1).

\section{Regionalization of nerve cords in protostomes and chordates}

Because the CNSs in protostomes and deuterostomes are in different positions, develop rather differently and are morphologically somewhat diverse, possible homologies between them have been highly contentious. Complicating the picture is that some of the genetic mechanisms for specifying $\mathrm{A} / \mathrm{P}$ positions in the CNS are common to the entire organism, including the general ectoderm exterior to the CNS, and are therefore not entirely useful for inferring homologies of CNSs. For example, some genetic mechanisms mediating $\mathrm{A} / \mathrm{P}$ patterning in the CNS were clearly inherited from a cnidarian-like ancestor in which they patterned the entire body axis. Thus, Six3/6 and Irx are expressed in the aboral region of the planula larva of the sea anemone Nematostella vectensis, opposite the blastopore [39] and in the anterior end of the brain of both protostomes and deuterostomes - Six3/6 in the anterior tip of the CNS and Irx genes a little more posteriorly [24,40-44]. In $N$. vectensis the domains of these two genes are initially congruent, while in the CNS of bilaterians the Six3/6 domain is anterior to that of Irx. Therefore, although it is most parsimonious to propose that these genes were coopted into the CNS of an ancestral bilaterian, it cannot be ruled out that they were coopted independently into the CNS of protostomes and deuterostomes.

Hox genes are another example of $\mathrm{A} / \mathrm{P}$ patterning genes that are not entirely useful for inferring homologies between the protostome and chordate CNS. The problem is that although they do mediate $\mathrm{A} / \mathrm{P}$ patterning of the CNS in bilaterians $[45,46]$, they mediate $\mathrm{A} / \mathrm{P}$ patterning of other tissues as well [47-54]. Thus, while their expression patterns have been used to infer homologies between the CNS in insects and vertebrates, it remains possible that they patterned the entire body axis of the Urbilaterian and were independently coopted into the CNSs of protostomes and deuterostomes. It is not clear when a role for nested expression of Hox genes in regionalization of the $\mathrm{A} / \mathrm{P}$ axis evolved. They do not appear to be involved in $\mathrm{A} / \mathrm{P}$ patterning in cnidarians [55,56]. Comparisons of Hox genes in protostomes with up to 10 or 11 Hox genes and invertebrate deuterostomes with up to 15 indicate that the ancestral bilaterian had at least eight to 10 Hox genes [57], while cnidarians have up to six depending on the species and acoel flatworms have three, which are more or less regionally expressed in the surface ectoderm along the $\mathrm{A} / \mathrm{P}$ axis $[58,59]$ with later expression in putative neural precursors [49]. Thus, acoels either arose before a large Hox cluster evolved or they lost some Hox genes. Even so, a role for an expanded array of Hox genes in specification of $\mathrm{A} / \mathrm{P}$ positions in the ectoderm was evidently present in the ancestral bilaterian. Thus, although expression of the Drosophila melanogaster Hox1 gene labial in a stripe at the posterior end of the tritocerebrum within the unpg $(G b x)$ domain has been likened to nested expression of Hox genes in the vertebrate hindbrain, with Hoxb1 being expressed in a stripe in rhombomere 4, the possibility that Hox genes were independently coopted into the CNS in protostomes and deuterostomes cannot be ruled out.

Stronger support for a single origin of the CNS comes from similar expression in the CNSs of protostomes and chordates of genes that are not expressed in comparable patterns in other tissues. Thus, Reichert and colleagues used gene expression patterns to support the perhaps surprising idea that the three parts of the Drosophila brain - protocerebrum, deutocerebrum and tritocerebrum $[5,45]$ - are homologous to the forebrain, midbrain and hindbrain of vertebrates (Figure 2) [60]. For example, in D. melanogaster, the Otx homolog Otd is expressed throughout the protocerebrum and deutocerebrum, while unpg (homologous to $G b x$ ) is expressed in the tritocerebrum, the subesophageal ganglion and the ventral nerve cord [5]. The domains of the two abut at the boundary between the deutocerebrum and tritocerebrum, similar to the abutting domains of $O t x 2$ and $G b x 2$ at the midbrain/ hindbrain boundary $(\mathrm{MHB})$ in vertebrates [5,61]. In addition, although some domains of $P a x 2 / 5 / 8$ genes are not similar between the CNS of flies and chordates, $\mathrm{Pax} 2 /$ $5 / 8$ is expressed at high levels in the posterior part of the deutocerebrum (just anterior to the deutocerebrum/tritocerebrum boundary) in D. melanogaster, while the three vertebrate $\mathrm{Pax} 2 / 5 / 8$ genes are expressed at high levels at the MHB [5,62]. Moreover, in third instar 
larvae of D. melanogaster, the earmuff gene (homologous to Fezf) is broadly expressed in the anterior brain with a posterior boundary at the protocerebrum/deutocerebrum boundary [63]. The domain is just anterior to that of mirror, one of the three $\operatorname{Ir} x$ homologs. Similarly, Irimia and colleagues showed that in chordates, the posterior limits of $\mathrm{Fez}$ genes (Fez and Fez-like) abut the anterior limit of Irx1 in the forebrain [64]. In vertebrates, this is the zona limitans intrathalamica (ZLI) [65].

Compatible with a single origin of the CNS, expression of the genes mediating $\mathrm{D} / \mathrm{V}$ patterning within the CNS is also conserved between protostomes and deuterostomes [66] (Figure 3). These genes are not comparably expressed in cnidarians, suggesting that they were recruited for roles in $\mathrm{D} / \mathrm{V}$ patterning the $\mathrm{CNS}$ of an ancestral bilaterian. Notably, homologs of some key genes expressed mediolaterally in the neuroectoderm of $D$. melanogaster embryos are expressed in comparable domains in the vertebrate CNS. Thus, the msh gene is expressed laterally in the D. melanogaster neuroectoderm, with ind expressed in an intermediate longitudinal domain and vnd expressed in a medial stripe of neuroblasts (reviewed in [7,67]). Vertebrate homologs of these three homeobox genes are comparably expressed in the developing neural tube. Two of the three msh orthologs (Msx1, $M s \times 2, M s x 3)$ are expressed dorsally (that is, laterally) in the roof plate of the CNS, one of the two ind orthologs (Gsh1) is expressed in the adjacent zone (alar plate), and one of the two vnd orthologs ( $N k x 2.2)$ is expressed more ventrally (that is, medially) in the basal plate.

Additional evidence for homology of protostome and chordate nerve cords, and thus a bilaterian ancestor with a CNS, comes from neuroanatomy, neuronal function and gene expression. Strausfeld and Hirth found striking parallels between the central complex in the arthropod protocerebrum and the basal ganglia in the ventral forebrain of vertebrates [3]. In particular, the vertebrate striatum and pallidum have similar organization as, respectively, the insect fan-shaped body and ellipsoid body. Both the types of neurons and their connections and the functions of these regions are similar in the two organisms. Taken together, the data from comparative gene expression and anatomy provide relatively strong support for a single origin of the CNS in insects and chordates.

\section{Parallels between the brains of annelids and vertebrates}

Additional evidence for a single origin of the CNS comes from comparisons between annelids and vertebrates. Not only have parallels been drawn between patterning the Drosophila and vertebrate brains, but Arendt and colleagues have also noted similarities between the genetic mechanisms patterning the nervous systems of the annelid Platynereis dumerilii and vertebrates $[2,81]$ (reviewed in [4]). The annelid brain varies from species to species, with the brains of some species lacking clear compartments but many others having such features as
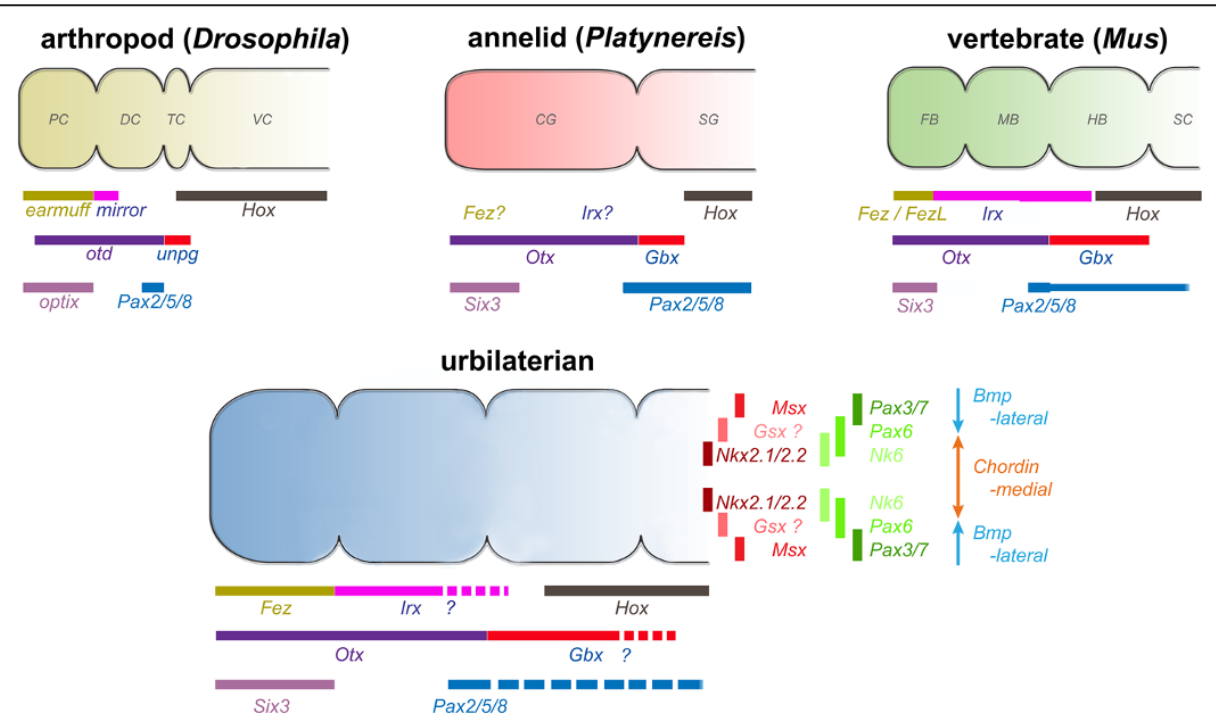

Figure 3 Anterior-posterior gene expression in central nervous systems of three extant bilaterians and the urbilaterian. Anteriorposterior regionalization of gene expression in the central nervous systems of three extant bilaterians (an arthropod, an annelid and a vertebrate) and inferred expression in the last common bilaterian ancestor, the urbilaterian. Expression of Fez and Irx in the annelid Platynereis is unknown. For the urbilaterian, both anterior-posterior and medio-lateral gene expression domains are shown. Hypothetical posterior limits of Irx and Gbx domains in the urbilaterian brain are highlighted by a "?" and dashed lines. PC, protocerebrum; DC, deutocerebrum; TC, tritocerebrum; VC, ventral nerve cord; CG, cerebral ganglion; SG, segmental ganglia; FB, forebrain; MB, midbrain; HB, hindbrain; SC, spinal cord. Gene expression domains based on $[1,2,9,24,29,34,42,64,68-80]$. 
complex, neuron-rich mushroom bodies (a comparatively large part of the brain in insects and annelids that integrates olfactory information) [82]. Extensive comparisons of gene expression have been used to argue for homology between the mushroom bodies and the pallium of the vertebrate brain [2,81]. For example, $B f-1$ (FoxG1) is expressed in the anterior part of the vertebrate telencephalon and the pallium as well as in the tip of the annelid brain, while Wnt5/8 is expressed in the vertebrate pallium and in the annelid mushroom bodies, flanking more medial expression of $H h$ in both [2].

Furthermore, in P. dumerilii Six3 and Otx are expressed anteriorly in the CNS (the peristomium) with the Six3 domain extending anterior to that of Otx [42]. The posterior limit of the Otx domain abuts that of $G b x$ in the first larval segment, while the anterior boundaries of Hox 1 and Hox 4 are in the second and third larval segments [48]. Six3/6 and Otx are similarly expressed in acoel flatworms $[26,83,84]$, and in D. melanogaster all three genes are expressed in similar patterns as in $P$. dumerilii. Therefore, the annelid cerebral ganglion has been homologized with the insect protocerebrum. In addition, similar to the CNS in Drosophila and vertebrates, the neuroectoderm in $P$. dumerilii is divided into a series of domains with outer/dorsal expression of $M s x$ and Pax3/7 (gooseberry), intermediate expression of Nk6 and Pax6, and medial expression of $N k x 2.1 / N k x 2.2$ [1].

Together with anatomical similarities, these data showing distinct similarities in expression of genes patterning the CNS both anteriorly/posteriorly and medio/ laterally between both major lineages of protostomes (Ecdysozoa and Lophotrochozoa) and vertebrates support a single origin of the CNS in the bilaterian ancestor (Figure 2). The counterargument would be that the CNS in protostomes evolved independently coopting $\mathrm{A} / \mathrm{P}$ and $\mathrm{D} / \mathrm{V}$ patterning mechanisms from an ancestor that used them to pattern a body axis. However, this would mean that the extensive similarities in neuronal architecture between chordates, arthropods and annelids would have been convergently evolved, which seems most unlikely.

\section{Was there a dorso/ventral inversion, and if so, when did it} occur?

If the CNS evolved just once, then a D/V inversion must have occurred during evolution of either protostomes or deuterostomes (reviewed in $[27,85]$ ). At present, the chief theories are as follows. The first is Anton Dohrn's idea that a $\mathrm{D} / \mathrm{V}$ inversion occurred either at the base of the protostomes or within the deuterostomes [86]. The second is the idea most recently articulated by John Gerhart, Christopher Lowe and colleagues that the ancestral deuterostome was hemichordate-like with dorsal and ventral nerve cords and an ectodermal nerve net, with the chordate CNS arising directly from the nerve net $[9,24,27]$ or alternatively, as proposed by van Wijhe [87] and more recently by Nomaksteinsky and colleagues [88], from the dorsal nerve cord. A third theory that the ancestral bilaterian had multiple nerve cords, with one evolving into the protostome CNS and another into the deuterostome CNS, was suggested by Gerhart [27] but has received little attention.

Major evidence supporting a D/V inversion in either basal deuterostomes, basal protostomes or basal chordates is that genes involved specifying polarity of the $\mathrm{D} / \mathrm{V}$ body axis are expressed in opposite orientations in protostomes and chordates. Sasai, de Robertis and colleagues found that in both groups, BMP signaling is involved in establishing $\mathrm{D} / \mathrm{V}$ polarity and in neural specification, with suppression of BMP signaling being a prerequisite for formation of a CNS $[22,23,89]$. In agreement with a D/V inversion having occurred in either the deuterostome or protostome lineages [23], BMPs are expressed dorsally in protostomes and hemichordates and the BMP antagonist short gastrulation (= chordin in deuterostomes) is expressed ventrally, while in chordates it is the opposite - BMPs are expressed ventrally and chordin dorsally. In most bilaterians, D/V orientation of the body and position of the nerve cord are coupled; however, Hejnol and Martindale have noted that expression of $B M P 2 / 4$ dorsally (opposite the future mouth) in an acoel with neurite tract(s) dorsally as well as laterally [26] supports the idea that a role for $B M P /$ chordin in axial patterning may have preceded a role in neural patterning. Another line of evidence supporting D/V inversion comes from analysis of genes involved in left-right patterning. For example, two key regulators of this distinction, Nodal and Pitx, are expressed on the left side of chordates, but on the right in echinoderms and in some molluscs [90,91].

In summary, conserved expression of some genes along the longitudinal axis of cnidarians and in the CNS and general ectoderm of bilaterians indicates likely cooption of roles for these genes in patterning the CNS. However, similar expression of genes involved in both $\mathrm{D} / \mathrm{V}$ patterning of the $\mathrm{CNS}$ and in $\mathrm{A} / \mathrm{P}$ regionalization of the brain in chordates and protostomes together with neuroanatomical parallels provides considerable support for the idea that the bilaterian ancestor had a CNS, which was modified or possibly lost in various protostome and deuterostome lineages.

\section{Hemichordate theories}

Despite considerable evidence in support of a single origin of the CNS, data from hemichordates have been interpreted as indicating that the ancestral deuterostome had a nerve net, and therefore the CNSs in chordates and protostomes evolved independently. Hemichordates and echinoderms form a clade, the Ambulacraria, which 
branched off the deuterostome tree as a sister group to chordates. Indirect developing members of both groups have similar pelagic larvae with an apical tuft of cilia. Echinoderms, which have pentamerous symmetry, typically have an ectodermal nerve net plus radial nerves and a circumoral nerve ring. While Haag proposed that the sea urchin radial nerves are homologous to the chordate CNS [33], most authors disagree [92,93]. Importantly, echinoderm nerve cords do not express Hox genes $[51,94,95]$, and an extensive screen by Sly and colleagues for expression of neural patterning genes in a juvenile sea urchin failed to find evidence that the nerve ring or radial nerves are homologous to any part of the brain or nerve cord in bilaterians [93]. Moreover, Engrailed is very broadly expressed in the nervous systems and other tissues of the juvenile starfish and not in localized domains as in the chordate CNS [94]. Therefore, echinoderms are currently not considered relevant to the question of evolution of chordate nerve chords. In contrast, the worm-like enteropneust hemichordates, which have longitudinal nerve cords as well as a nerve net, have figured prominently in discussions of the evolution of chordates [10,96-98].

Inferring homologies between chordate nerve cords and hemichordate nervous tissues has been complicated by large differences in morphology. Adult hemichordates have three distinct regions: proboscis, collar and trunk. There are two classes of hemichordates - enteropneusts and pterobranchs. All four families of enteropneusts (Harrimaniidae, Spengelidae, Ptychoderidae, Torquaratoridae) have an ectodermal nerve net, located in all three regions, plus dorsal and ventral nerve cords, suggesting that this organization is a basal hemichordate characteristic. In contrast, the sessile pterobranchs have anterior tentacles and a concentration of neurons at the base of the tentacles that has been termed a brain, as well as several concentrations of neurites and associated neurons extending into the tentacles, the stalk and between the gill slits [99]. Although Romer and others argued that pterobranchs were basal hemichordates $[100,101]$, recent molecular phylogenetic analyses do not distinguish which family is basal [102,103], leaving open the possibility that pterobranchs are derived. Indeed, fossil tube-dwelling enteropneusts from the Cambrian were recently discovered [104].

Most of the work on neural development in hemichordates concerns indirectly developing ptychoderids and the direct developing harrimaniid Saccoglossus kowalevskii (reviewed by Röttinger and Lowe [105]). Miyamoto and colleagues showed that the larval nervous system in indirect ptychoderids does not carry over into the adult; in late larvae, the larval nervous system is gradually replaced by the adult one [106]. Therefore, it is the development of the adult nervous system that is pertinent for understanding evolution of the CNS.

\section{Hemichordates and the argument of an ectodermal nerve net versus a CNS: theory one}

There are two competing theories concerning the evolutionary relationship between the nerve net and nerve cords of hemichordates and the chordate CNS (Figure 1). One theory, most recently articulated by Kaul and Stach [107], proposes that one of the hemichordate nerve cords, typically the dorsal one, is homologous to the chordate CNS. This theory implies that the ancestral deuterostome and perhaps also the ancestral bilaterian had a CNS. The chief basis for this idea is that the collar nerve cord neurulates, suggestive of neurulation in vertebrates $[88,108]$. Anterior and posterior to the collar, the nerve cord is continued by basiepithelial tracts of neurites, which are concentrated dorsally [99]. However, there is nothing that resembles a brain. In the direct developing S. kowalevskii, neurulation in the collar nerve cord progresses from posterior to anterior, and there are posterior and anterior neuropores [107]. The nerve cord continues posteriorly as a superficial tract of nerve cell bodies overlying nerve cell fibers and rostral of the anterior neuropore as a wide, superficial tract of both neurons and nerve fibers [88]. In addition to the longitudinal nerve cords, there is a peribranchial nerve ring, which develops from ventral to dorsal, as well as a collar nerve ring at the collar-trunk boundary. Although initially neither nerve cord was thought to contain nerve cell bodies, studies with electron microscopy and with specific nerve cell markers have demonstrated nerve cell bodies and glia in the dorsal nerve cord and at least some neurons associated with the ventral one $[107,109,110]$. Ventrally in the dorsal cord, there is a neuropil. Bullock [111] and Brown and colleagues [110] have suggested that the large neurons may be homologous to Mauthner cells of the lamprey and Rhode cells of amphioxus. The developing collar and ventral nerve cords as well as the peripharyngeal cord of both Ptychodera flava and S. kowalevskii express nerve cell-specific genes including Elav, synaptogamin and also genes for peptides and proteins specific for subsets of nerve cells including VAChT, serotonin, Hb9, Drg11 and GABA. Serotonergic neurons are restricted to the peripheral nervous system, while those labeling with $\operatorname{Drg11}, \mathrm{Hb} 9$ and cholinergic neurons are preferentially in the collar nerve cord $[88,112]$.

Although most of the ptychoderid ectoderm is nonneural [88], basiepithelial nerve cells are moderately numerous in the proboscis [106]. Nomaksteinsky and colleagues suggested that the more even distribution of neurons in the basiepithelial nerve net of S. kowalevskii might represent a transient larval nervous system and 
that part of the diffuse nervous system of developing $S$. kowalevskii larvae, especially in the proboscis, will become the peripheral nervous system [88]. Based on the morphological and gene expression data, they concluded that it was implausible that the enteropneust skin is homologous to the chordate CNS'. Instead, they argued that the relatively few neurons in the adult "non-neural" ectoderm constituted a peripheral nervous system, and that either the dorsal or ventral nerve cord (they could not decide which one) was homologous to that of chordates [88]. A comprehensive study of developmental gene expression in the developing nerve cords of hemichordates is sorely needed; to date only a few pictures showing expression of genes including $D l x$, several Hox genes, Tbx2/3, PoxN, Pitx and Olig in the dorsal and/or ventral midline of embryos of $S$. kowalevskii have been published $[9,24,25,113]$, but whether the tissue expressing these genes is the developing nerve cord or overlying ectoderm is not clear. There are no studies of developmental gene expression in indirectly developing species such as $P$. flava due to a long pelagic larval period $[114,115]$.

A problem with homologizing the dorsal nerve cord of hemichordates with the chordate CNS is the finding by Lowe and colleagues [113] that, as in protostomes, BMP2-4 and BMP5-8 are expressed dorsally in $S$. kowalevskii, while chordin is expressed ventrally. Consistent with a role in D/V patterning, excess BMP4 protein radializes the embryos and eliminates chordin expression, indicating an evolutionarily conserved role of BMP in D/V patterning. This suggests that if either nerve cord in hemichordates is homologous to the chordate CNS, it is the ventral nerve cord, which does not neurulate, and a D/V inversion occurred at the base of the chordates. This is consistent with the gill slits being dorsal and the stomochord, a dorsal/anterior extension of the gut, having been shown to be unrelated to the notochord [116]. Confusing the issue further, in amphioxus and vertebrates, Nodal expression dorsally acts in opposition to BMP expression ventrally [117], while in sea urchin embryos, BMPs and Nodal oppose each other in patterning the oral/aboral axis (Nodal ventralizes; BMP dorsalizes), suggesting that a role for Nodal in opposing BMPs was present at the base of the deuterostomes and that a $\mathrm{D} / \mathrm{V}$ inversion occurred in chordates. To some extent this is similar in $S$. kowalevskii, in that perturbation of Nodal signaling results in D/V patterning defects [118]. However, treatment with the Nodal inhibitor SB431542 eliminates expression of both $B M P 2 / 4$ and chordin and anteriorizes embryos, indicating that Nodal posteriorizes embryos, the opposite of the situation in chordates [118]. These results suggest that the role of Nodal [119] may have been altered in $S$. kowalevskii. Whether a role for BMP/Nodal opposition in $\mathrm{D} / \mathrm{V}$ patterning was present in the ancestral bilaterian is uncertain. Nodal is involved in left/right patterning in a mollusk [120], but possible roles in $\mathrm{D} / \mathrm{V}$ or $\mathrm{A} / \mathrm{P}$ patterning in protostomes have apparently not been investigated. In summary, since it neurulates, the dorsal nerve cord of hemichordates has been proposed as homologous to the chordate CNS. However, the rather scanty data on gene expression are more compatible with homology of the ventral nerve cord and the chordate CNS. More data are clearly needed on both anatomy and gene expression in the hemichordate nerve cords.

\section{Hemichordates and the argument of an ectodermal nerve net versus a CNS: theory two}

In spite of the evidence supporting the idea that the ancestral bilaterian had a CNS, there is an alternative theory - namely that the ancestral bilaterian and the ancestral deuterostome had ectodermal nerve nets, from which the chordate CNS evolved. The dorsal and ventral nerve cords of hemichordates are therefore not only a hemichordate invention, but are unrelated to the chordate CNS (reviewed in [34]). This theory, most recently articulated by Lowe and colleagues $[9,24,113]$, is based on developmental gene expression and gene interactions in the direct-developing hemichordate, S. kowalevskii. It proposes that the chordate CNS evolved from the ectodermal nerve net of a hemichordate-like ancestral deuterostome and maintains that the hemichordate nerve net contains signaling centers evolutionarily related to the anterior neural ridge (ANR), the ZLI and the isthmic organizer (ISO) in vertebrates. As a corollary, part or all of these signaling centers have been lost in the invertebrate chordates (amphioxus and tunicates) [9]. This idea deserves careful consideration because it not only argues that the considerable similarities of gene expression in protostome and chordate nerve cords represent convergent evolution, but it assigns a key position to hemichordates in evolution of the vertebrate CNS.

de Beer [121] was one of the first to recognize the hierarchical nature of homology when he noted similar morphological features in two different animals could develop under the control of different genes; a phenomenon now known as genetic piracy [122]. The converse is also known - where parts of homologous gene networks are involved in the development of apparently nonhomologous structures [123]. When such disconnects are discovered, some would pay more attention to structure [124], and others would pay more attention to the genes (as a deep homology) [125]. In discussing neural evolution in higher deuterostomes, Lowe and colleagues strongly favor genes over morphological features as arbiters of homology. Thus, they maintain that structures with very different morphology (for example, the proboscis of a hemichordate and the forebrain of a 
vertebrate) are not morphologically homologous [25,126] even though conserved gene expression patterns may indicate a common evolutionary origin. Thus, while those authors find that homologous genetic programs operate at the anterior end of the hemichordate proboscis and vertebrate ANR, at the boundary between the hemichordate proboscis and collar and at the vertebrate ZLI, and at the boundary between the hemichordate collar and trunk and at the vertebrate ISO located at the MHB, they do not refer to these three regions of the hemichordate ectoderm and vertebrate brain as homologs [9]. Even so, as discussed by Wagner [16], these regions could be homologous even though morphologically divergent.

Lowe and colleagues, in their series of papers concerning genes and structures involved in neural evolution of deuterostomes, have been somewhat inconsistent in their treatment of the subject of homology. In their initial work, which concerned expression of 22 genes with restricted ectodermal domains along the A/P axis (Table 1), they concluded that the surface ectoderm of $S$. kowalevskii and the chordate CNS have a common ancestry [24]. These authors noted that S. kowalevskii 'shows pervasive neurogenesis with no large, contiguous non-neurogenic subregion, as occurs in chordates' and concluded that the deuterostome ancestor had a diffuse ectodermal nerve net that evolved into the vertebrate CNS [24]. One difficulty with this argument is that, as Aronowicz and Lowe [25] later noted, the surface ectoderm of invertebrate chordates outside the neural tube contains widespread ectodermal sensory neurons (Figure 1) $[127,128]$, while in vertebrates the large panplacodal region outside the neural plate is highly neurogenic [68]. In addition, although the authors maintained that most of 22 genes they studied are not expressed in

Table 1 Gene expression in nervous tissues of -Saccoglossus kowalevskii, Branchiostoma floridae, Ciona intestinalis and vertebrates

\begin{tabular}{|c|c|c|c|c|c|c|c|c|c|}
\hline \multirow[t]{2}{*}{ Gene } & \multicolumn{2}{|c|}{ S. kowalevskii } & \multicolumn{2}{|c|}{ B. floridae } & \multicolumn{2}{|c|}{ C. intestinalis } & \multicolumn{2}{|l|}{ Vertebrate } & \multirow[t]{2}{*}{ References } \\
\hline & s.e. & $\mathrm{CNC}^{\mathrm{a}}$ & s.e. & $\overline{\text { CNS }}$ & Ectoderm & CNS & Placode & CNS & \\
\hline SOXB & + & + & + & + & + & + & + & + & {$[131]$} \\
\hline Hu/Elav & + & + & + & + & $?$ & $?$ & + & + & \\
\hline Nrp/Musashi & + & + & + & + & $?$ & + & + & + & [141] \\
\hline Vax & + & - & $?$ & $?$ & gene & lost & - & retina, forebrain & [142] \\
\hline$R x$ & + & - & - & + & - & + & - & + & {$[69,76]$} \\
\hline Six3 & + & $+/-$ & + & + & - & + & - & + & {$[43,131,143]$} \\
\hline$N k \times 2.1$ & + & - & - & + & $?$ & $?$ & - & + & {$[140,144]$} \\
\hline$B f-1$ & + & $+/-$ & + & + & + & $?$ & + & + & {$[131,145,146]$} \\
\hline$D / x$ & + & + & + & + & + & + & + & + & {$[77]$} \\
\hline Pax6 & + & + & + & + & - & + & + & + & [75] \\
\hline$T I I / T / x$ & + & $+/-$ & + & + & $?$ & $?$ & + & + & {$[147,148]$} \\
\hline $\mathrm{BarH}$ & + & + & $?$ & $?$ & $?$ & $?$ & + & + & [149] \\
\hline Emx & + & + & $?$ & $?$ & $?$ & $?$ & + & + & [150] \\
\hline Otp & + & $?$ & $?$ & $?$ & + & + & $?$ & + & {$[131,151]$} \\
\hline$D b x$ & + & + & $?$ & $?$ & $?$ & $?$ & - & + & [152] \\
\hline $\operatorname{Lim} 1 / 5$ & + & + & + & + & $?$ & $?$ & + & + & [153] \\
\hline Irx & + & + & + & + & $?$ & $?$ & + & + & [154] \\
\hline Otx & + & + & - & + & + & + & + & + & {$[78,137]$} \\
\hline En & + & + & + & + & - & + & + lamprey & + & {$[78,155]$} \\
\hline Gbx & + & + & + & + & gene & lost & + & + & [142] \\
\hline Hox1 & + & + & + & + & + & + & + & + & [156-158] \\
\hline Hox3 & + & - & + & + & + & + & + & + & {$[134,156,158]$} \\
\hline Hox4 & + & $?$ & + & + & - & - & - & + & [156] \\
\hline Hox7/8 & + & $?$ & $?$ & $?$ & gene & Lost & - & + & [156] \\
\hline Hox11/13 & + & - & $?$ & $?$ & Hox12+ & Hox12+ & Hox11+ & + & {$[156,159]$} \\
\hline
\end{tabular}

Gene expression in ectoderm and nervous tissue of the hemichordate Saccoglossus kowalevskii, the cephalochordate Branchiostoma floridae, the tunicate Ciona intestinalis and vertebrates. Note: En expression in placodes only documented for lamprey among the vertebrates. CNC, collar nerve cord; CNS, central nervous system; s.e., surface ectoderm. ${ }^{\mathrm{a}}$ In the absence of sections, which would distinguish between expression in the surface ectoderm and in the collar nerve cord, all genes with ectodermal expression in the region of the dorsal portion of the collar are listed. 
the "epidermal ectoderm" in chordates [24], in the 10 years since this paper was published, it has become clear that all except possibly $\operatorname{Vax}, R x$ and $N k x 2-1$ are expressed in ectodermal sensory cells in chordates (Table 1) [68,129-131]; expression of Vax in amphioxus and of $N k \times 2-1$ in the tunicate Ciona intestinalis have not been determined. For example, Sox 1/2/3 (SoxB) and $\mathrm{Hu} /$ Elav are expressed in ectodermal sensory cells in chordates [129,130], Hox1, Hox3 and Hox4 are expressed in nested patterns in the amphioxus ectoderm and at especially high levels in ectodermal sensory cells [132], ascidian Hox 1 is expressed in development of ectodermal sensory cells [133], and some Hox genes are expressed in placode derivatives in vertebrates [134]. In addition, $G b x$ is expressed in the "non-neural" ectoderm in amphioxus [135] and in developing placodes in vertebrates [136], while $G b x$ and $O t x 2$ mutually repress one another in development of the otic placode as they do in A/P patterning of the CNS [137]. Therefore, as noted above, the ectodermal expression patterns of genes along the $\mathrm{A} / \mathrm{P}$ axis do not clearly distinguish CNS from ectoderm outside the CNS. Indeed, Aronowicz and Lowe noted that genes such as Otx and Hox appear to be involved in patterning neurogenic tissues generally [25]. Thus, expression of these A/P patterning genes alone does not distinguish between theories that the ancestral bilaterian and ancestral deuterostome had an ectodermal nerve net or whether they both had a CNS. As noted above, genes expressed exclusively in the CNS of bilaterians (for example, earmuff/Fezf/Fezl and D/V patterning genes) are generally more informative for inferring the course of evolution of the CNS [64]. Indeed, domains of homologs of three genes mediating lateral to medial (D/V) patterning in the chordate and protostome CNSs (Hh, Nkx2.2, Msx) [138-140] are not expressed in comparable patterns in the hemichordate ectoderm [113]. Thus, if the chordate CNS evolved from a nerve net in the ancestral deuterostome, expression of these lateral to medial genes would represent convergent evolution in the CNSs of protostomes and chordates.

The similarities in patterning the ANR and the anterior part of the hemichordate proboscis, the ZLI and the boundary between the proboscis and collar, and the ISO and the boundary between the collar and trunk lead to the conclusion that in the ancestral deuterostome the role for these signaling centers, which ultimately gave rise to the vertebrate ANR, ZLI and ISO, was to regionalize the general body plan [9]. However, Pani and colleagues also proposed that amphioxus partially lost the ANR, and completely lost both the ZLI and ISO, while the tunicate $C$. intestinalis lost the ZLI and partially lost both the ANR and ISO [9]. They conclude that in 'certain cases hemichordates will be a more informative group than basal chordates for reconstructing stem chordate characters and understanding the origins of vertebrate developmental genetic processes' [9]. As this is quite an extreme view and is at odds with conclusions based on morphology, gene expression and gene function in amphioxus, tunicates and vertebrates, the evidence merits close examination.

\section{How much of the ANR gene network is present in S. kowalevskii? Is the evidence sufficient that the vertebrate ANR evolved from the anteriormost ectoderm of the ancestral deuterostome?}

The vertebrate ANR is characterized by expression of Fgf8, Six3, Pax6, Otx2, Sox2 with Dlx5 expressed in adjacent non-neural ectoderm and $B f-1$ (FoxG-1) expressed in the rostral forebrain (Figure 4) [160], while Sfrp1a is expressed in the anterior/ventral part of the developing neural tube [161]. In addition, transplantation of the ANR laterally expanded the telencephalon and promoted expression of $B f-1$ (FoxG1), demonstrating that the ANR is an organizer [162]. In S. kowalevskii, homologs of these genes are expressed in the proboscis ectoderm, although their relative domains are rather divergent from those of their homologs in the vertebrate forebrain. For example, Six3, Sfrp1/5 and Fgf8/17/18 are strongly expressed in the anterior proboscis ectoderm, and Sox 1/ $2 / 3$ is broadly expressed in the proboscis and anterior part of the collar [9]. However, Pax6 is not expressed at all in the anteriormost proboscis ectoderm but more posteriorly throughout much of the proboscis and collar, while Otx is chiefly expressed in the collar ectoderm with only very weak expression at the anterior end of the proboscis. In addition, $D l x$ is very patchily expressed in the proboscis ectoderm, but appears to be highly expressed where the dorsal nerve cord will form. $H h$ is expressed in ectoderm at the tip of the proboscis in $S$. kowalevskii [9], while in vertebrates it is expressed in the basal plate of the forebrain and midbrain and in the floor plate of the anterior hindbrain as well as in the prechordal plate [163].

Experimental evidence for homology of gene networks patterning the ANR and anterior proboscis ectoderm in S. kowalevskii came from manipulation of Fgf and $\mathrm{Hh}$ signaling. Although inhibition of Fgf or Fgf signaling scarcely affected expression of the proboscis domain of the anterior marker $R x$, it did eliminate FoxG1 (BF-1) expression in the proboscis. In addition, knockdown of Hh eliminated expression of the anterior marker Fgf-Sk1. Thus, inhibition of Fgf or Hh signaling affects development of the proboscis and expression of some anterior markers. However, Green and colleagues found that the major role of $F g f 8 / 17 / 18$ in development appears to be in mesoderm induction [164]. Therefore, the effects of inhibition of Fgf signaling on anterior development could be secondary to those on mesoderm. 


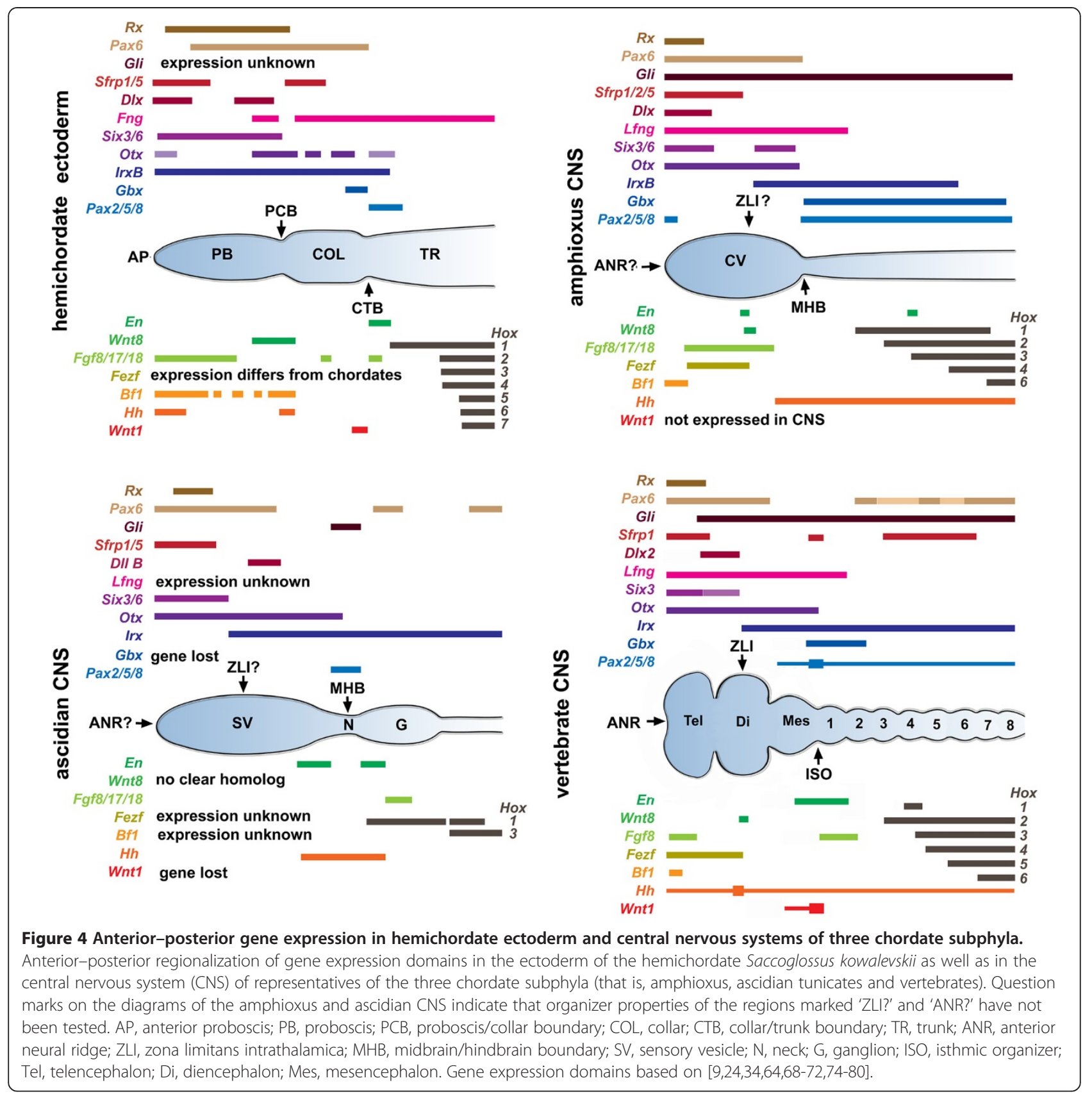

Whether this evidence is sufficient to indicate that the vertebrate ANR evolved from the anterior part of a diffuse ectodermal nerve net in the deuterostome ancestor is open to question. A major difficulty in identifying homologous gene networks is deciding how much of two gene networks must be conserved for them to be considered homologous [165]. This is a particular problem when the morphology is not conserved. Gene networks can include several thousand genes, and it is well known that core parts of signaling pathways are often coopted for patterning nonhomologous structures [166]. Thus, there are several alternative explanations for similarities in gene expression between the hemichordate proboscis ectoderm and the vertebrate ANR. One is that similar expression of a suite of genes including $F g f s$ in these two regions may simply be indicative of ancient roles in specification of the anterior end of embryos in general. For example, Sinigaglia and colleagues reported that Six3/6, FoxQ2, Irx, SoxB1 and Fgf are expressed in the aboral region in the cnidarian $N$. vectensis, while Wnts are expressed at the opposite end of the embryo [39]. Six3/6 is initially involved in specification of the anterior end of the embryo and later in neurogenesis. Fgf signaling is required for development of the apical tuft 
of cilia. Therefore, roles for these genes in patterning the hemichordate proboscis may simply reflect an inheritance from prebilaterians. Another possibility is that if, as comparisons of protostomes and chordates indicate, these genes were coopted for patterning the anterior CNS of the ancestral bilaterian, then the ancestral deuterostome might have had a more extensive CNS than modern hemichordates. If so, the forebrain may have been lost as the proboscis evolved, and the genetic pathways for anterior neural development coopted into the proboscis ectoderm. Expression of $R x, F g f 8 / 17 / 18$ and other genes in the hemichordate proboscis is compatible with either theory. In chordates, $R x$ expression is apparently restricted to the anterior end of the forebrain (it is not expressed in sensory ectoderm) [69], while Fgf8/ $17 / 18$ is expressed in the ANR and telencephalon of vertebrates as well as throughout the forebrain of amphioxus. In contrast, $H h$ is expressed in the anterior tip of the notochord in amphioxus and in the floorplate but not in the anterior CNS. Given that Fgf8 and Hh have been coopted in vertebrate limbs, which evolved in gnathostomes, for patterning the apical ectodermal ridge (AER) and zone of polarizing activity (ZPA) [167], it is certainly possible that these genes plus $R x$ and other genes involved in neuronal specification may have been coopted for patterning the proboscis ectoderm of hemichordates.

Another possibility, proposed by Nomaksteinsky and colleagues [88], is that the ectoderm of developing $S$. kowalevskii may represent a transient larval nervous system unrelated to that of the adult. Evidence is that SoxB genes, which mark the neural plate in chordates, are broadly expressed in the ectoderm of indirectly developing embryos of the hemichordate Ptychodera flava, with expression becoming localized during development to the stomodaeum, ciliary bands and apical ciliary tuft [114]. Dlx is expressed in the aboral ectoderm, with a concentration towards the apical tuft, and $F z 5 / 8$ and FoxQ2 are expressed in the apical tuft [168]. Similarly in S. kowalevskii, Six $3, F z 5 / 8$ and $D l x$ are broadly expressed in the proboscis ectoderm and $B f-1$ (FoxG1) in the apical region $[9,24]$. The tornaria larva of indirect developing hemichordates has much in common with the dipleurula type of echinoderm larvae, which also have an apical tuft and a band of cilia around the mouth. Moreover, gene expression in the apical tuft and surrounding ectoderm is highly conserved in the sea urchin and hemichordate larvae, and there is considerable similarity with expression in the proboscis ectoderm of $S$. kowalevskii embryos [169]. In sea urchins, FoxQ2, Fzl5/8, Sfrp1/5, Dkk3 and Six3 are expressed at the apical end of the larva, with Wnt signaling acting to restrict expression of these genes to the anterior end of the larva $[169,170]$. Similarly, in S. kowalevskii knocking down the Wnt receptor
$F z 5 / 8$ results in a posterior expansion of the domains of anterior markers [9], indicating that Wnt signaling is also regulating expression of genes in the proboscis ectoderm as it is in the apical ectoderm of sea urchin larvae.

\section{How much of the ZLI gene network is present in S. kowalevskii Does the evidence support evolution of the vertebrate $\mathrm{ZLI}$ from a boundary partitioning the anterior/ posterior axis of the ancestral deuterostome?}

The vertebrate ZLI is positioned and regulated, at least in part, by anterior expression of Otx and Fezf abutting a posterior domain of Irx [171,172]. Organizer properties are conferred by $H h$, which is expressed at the ZLI and which is regulated by Wnt8b (Figure 4) [173]. In fish, knockdown of Fezf2, which is expressed anterior to Irx, eliminates the prethalamus and causes mis-specification of the ZLI. Correspondingly, knockdown of Otx inhibits expression of Shh at the ZLI and reduces expression of $P t c 1$ and $W n t 8 b$ [172]. Evidence for organizer properties of the vertebrate ZLI comes from grafting experiments and implants of Fgf8-coated beads, which induce the rostral neuroepithelium to develop an ectopic and polarized mesencephalon/metencephalon (reviewed in [174]).

The region of the hemichordate ectoderm expressing homologs of ZLI genes lies at the boundary between the proboscis and the collar [9] and is marked by the posterior limit of $R x$ expression and bands of $F g f 8 / 17 / 18$, FoxG, Otx, Wnt8, Hh, Ptch, FoxA and Dlx. Congruent expression of Wnt8 and Hh in S. kowalevskii is consistent with a possible role of $W n t 8$ regulating $H h$ as it does at the ZLI in vertebrates. However, domains of Fezf and Irx, which abut at the ZLI in vertebrates, do not abut at the proboscis/collar boundary in S. kowalevskii. Expression of Fezf was not shown, but the major domain of Irx appears to be congruent with that of engrailed in the posterior part of the collar [24].

For S. kowalevskii, the experimental evidence presented by Pani and colleagues for the proboscis/collar boundary region acting as a signaling center was that knockdown of Otx expression reduced the intensity of the stripe of $H h$ expression just posterior to the proboscis/collar boundary, while inhibition of $\mathrm{Hh}$ signaling downregulated $D l x$ both at the proboscis/collar boundary and more anteriorly and also reduced the size of the proboscis [9]. These results show that Otx may act upstream of $H h$ at the proboscis/collar boundary, while $H h$ is vital for normal development. However, Otx and Shh also interact in patterning the vertebrate midbrain, not just the ZLI, and knockdown of Otx results in dorsal expansion of the Shh domain and a dorsal and anterior rotation of the MHB [175]. Thus, the relationship between $O t x$ and $H h$ and perhaps some other parts of the gene network may be evolutionarily conserved between $S$. kowalevskii and vertebrates, but whether tissue at the 
proboscis/collar boundary in an ancestral deuterostome evolved into the ZLI is open to question given the markedly different expression of key genes such as Fezf and Irx as well as the lack of anatomical similarity.

\section{How much of the ISO gene network is present in S. kowalevskii Does the evidence support evolution of the vertebrate ISO from a boundary partitioning the anterior/ posterior axis of the ancestral deuterostome?}

In the vertebrate CNS, the MHB or isthmus functions as an organizer, and is therefore termed the isthmic organizer or ISO. The MHB is positioned by opposition of anterior Otx and posterior Gbx. Organizer properties are conferred by the action of a suite of genes including $E n$, Fgf8/17/18, Wht1 and Pax2/5/8 (Figure 4) [176]. Otx and $F g f 8$ are expressed in the midbrain and $G b x$ in the anterior hindbrain, with the Wnt1, Engrailed and Pax2/ 5/8 domains spanning the boundary; mutual repression of Otx and Gbx positions the ISO, and Wnt signaling is required for expression of Engrailed. Pani and colleagues also presented evidence for a homologous gene network in S. kowalevskii operating at the boundary between the collar and trunk [9]. Engrailed, Fgf8/17/18, Wnt1 and $G b x$ are expressed near this boundary. In addition, clonal suppression of $\beta$-catenin effectively inhibited $E n$ grailed expression, suggesting that Wnt signaling regulates Engrailed, as it does at the ISO in vertebrates, while suppression of Fgf8/17/18 reduced Engrailed expression at the collar/trunk boundary. However, despite these similarities, there are several problems in interpreting the gene network at the collar trunk boundary in S. kowalevskii as homologous to that patterning the vertebrate ISO. Importantly, as the authors note, the 'spatial arrangements of Otx and Wnt1, and Gbx and Fgf8/17/18 are reversed in S. kowalevskii compared to the ISO in vertebrates' [9]. Moreover, suppression of Fgf signaling had no effect on expression of $P a x 2 / 5 / 8$. A problem in interpreting these experiments is that in vertebrates, Fgf8 has an early role in induction of neural tissue, while patterning the ISO is a relatively late role. In $S$. kowalevskii, Fgf8/17/18 is expressed from the blastula stage, and by the neurula stage expression is restricted to anterior ectoderm. Knockdown experiments show that $F g f 8 / 17 / 18$ is required for mesoderm induction [164]. Therefore, effects of $F g f 8 / 17 / 18$ inhibition in $S$. kowalevskii on Engrailed expression may be secondary to the loss of mesoderm and not directly related to effects on A/P patterning. Additional evidence for the common ancestry of the collar/trunk boundary and the vertebrate ISO was that Hox genes are expressed in nested patterns in the trunk ectoderm. However, it appears that at least Hox 1 and perhaps Hox4 are also expressed in the dorsal part of the collar (Figure five in [24]), indicating that Hox expression in the ectoderm is probably not congruent with that in the collar, and raising the question of the genetic mechanisms patterning the collar nerve cord and how they might compare with those in chordates.

As for the ANR and ZLI, drawbacks to interpreting the boundary of the collar and trunk in hemichordates with the vertebrate ISO as having common ancestry not only include differences in expression of key genes expressed in these regions and also the general phenomenon of cooption of parts of gene networks for new functions. For example, in the AER of the vertebrate limb bud, Wnt3a induces expression of $F g f s$, while ectopic Engrailed (En-1) induces ectopic Fgf8 expression $[177,178]$. Moreover, in amphioxus, engrailed is coexpressed with Wnt8, but not at the MHB, suggesting that coexpression of $\mathrm{Wnt}$ and engrailed is not wedded to the MHB. The questions therefore become: how conserved must gene networks be in order for one to be reasonably certain that two morphologically rather different structures have a common ancestry; and if they do share an ancestry, can one distinguish whether portions of the gene networks operating in the CNS of a deuterostome ancestor were transferred to the hemichordate ectoderm as the hemichordate CNS became reduced or whether the ancestral deuterostome lacked a CNS and used these gene networks to partition the $\mathrm{A} / \mathrm{P}$ axis?

\section{How much of the ANR, ZLI and ISO do invertebrate chordates have?}

In addition to asserting that the $S$. kowalevskii ectoderm is not only homologous to the vertebrate CNS but also has homologs of the ANR, ZLI and ISO, Pani and colleagues maintain that the invertebrate chordates, amphioxus and tunicates, have lost all or part of these three regions [9]. Here we draw attention to data that are not consistent with such a view (Figure 4).

Although transplantation experiments in vertebrates demonstrated that the ANR functions as an organizer [163], such transplantation experiments are not feasible for hemichordate, amphioxus or $C$. intestinalis embryos due to their small size. However, it is clear that much of the gene network for specification of the ANR and conferring organizer properties upon it is present in amphioxus. Fgf8/ $17 / 18$ is expressed in the entire forebrain of amphioxus, and $B f-1$ (FoxG1) is expressed at the tip of the forebrain [145] as are Pax2/5/8 and Six3/6 [43]. Otx and Pax6 are expressed in comparable patterns with strong expression in the anterior forebrain [135,179], and the Wnt antagonist Sfrp1/2/5 is expressed in the anteriormost dorsal ectoderm, including the most anterior neuroectoderm [180]. Moreover, as in vertebrates, $D l x$ is expressed in ectoderm outside the neural tube as well as in the edges of the anterior neural plate [70], while $\mathrm{Hh}$ is expressed in the underlying 
tip of the notochord [181,182]. Taken together, these expression patterns indicate that amphioxus has most of the components for an ANR comparable to that in vertebrates.

Tunicates have undergone some radical changes to their genome and their anatomy in evolution. For example, the $G b x$ gene has been lost, and there are relatively few neurons - none in the tail nerve cord of ascidians. Otx is expressed anteriorly in the CNS, but the evidence for an ANR in C. intestinalis is relatively weak. In addition to Otx, Pax6 is expressed in the anterior CNS, but not $F g f 8 / 17 / 18$ and $P a x 2 / 5 / 8$, $H h$, or Gli [183]. Expression of $B f-1$ is not known. Therefore, it may be that as tunicates adopted early decision of cell fates and decreased the number of cells in the nerve cord, the need for an anterior brain organizer diminished.

For the ZLI, patterns of gene expression indicate that amphioxus probably has much of the genetic mechanism in place. In amphioxus, Irimia and colleagues showed that anterior expression of Fezf abuts posterior expression of IrxB about the midpoint of the forebrain [64] approximately where Wnt8 is expressed [184]. Similarly, Wnt $8 b$ expression at the ZLI in vertebrates is flanked by Lfng, while in amphioxus the Fng domain appears to be posterior to and possibly abutting that of the Wnt8 domain at the late neurula stage [184,185]. Dlx, Nkx2-2 and Gli, which mediates Hh signaling, are also expressed in this region, while $F g f 8 / 17 / 18$ is expressed throughout the forebrain $[70,71,186]$. Hh is expressed in the floor plate as it is in vertebrates, but it is unclear at the early neurula stage whether it is expressed congruently with Engrailed and Wnt8 or a little more posteriorly. Later expression is limited to a zone posterior to the forebrain [181]. Inhibition of Fgf signaling at the late blastula does not inhibit expression of neural plate markers, but eliminates that of Otx in the cerebral vesicle (forebrain) and reduces its size [187], indicating that Fgf signaling is essential for development of the forebrain. Similarly, upregulation of $\mathrm{Wnt} / \beta$-catenin signaling reduces expression of $O t x$ in the forebrain and eliminates expression of the anterior marker FoxQ2 [188], showing that suppression of $\mathrm{Wnt} / \beta$-catenin signaling by inhibitors such as Sfrp1/2/5 [180] is essential for forebrain development.

For ascidians, expression of Irx and Fezf is not known. C. intestinalis has two Wht genes that are possibly related to Wnt8 but which have long branches in phylogenetic analyses and for which assignation remain unclear [189]. Expression of these genes has not been characterized. However, Gli, Hh and Fgf8/17/18 are not expressed in the anterior CNS. Even so, inhibition of Fgf signaling blocks expression of the anterior marker Six3/ 6, indicating that Fgf signaling is required for development of the anterior brain [190]. Thus, while $C$. intestinalis likely lacks most of the gene network specifying the vertebrate ZLI and conferring organizer properties, until the expression patterns of Irx and Fezf are known the presence of part of the network for specification of the ZLI cannot be ruled out.

Amphioxus also appears to have in place the genetic mechanism for positioning the ISO, but this region does not express homologs of the genes that confer organizer properties on the vertebrate ISO. In the amphioxus brain, as in that of vertebrates, the domain of Otx expression in the forebrain/midbrain abuts that of $G b x$ in the hindbrain [135]. In vertebrates, organizer properties are conferred on the ISO by expression of Fgf8, Wnt1, Engrailed and Pax 2/5/8 genes at this boundary. In amphioxus, Wnt1 and Engrailed are not expressed between the Otx and Gbx domains, although $F g f 8 / 17 / 18$ is expressed anterior to and abutting this boundary, while Pax2/5/8 is expressed posterior to and abutting it $[187,191,192]$. Engrailed is expressed together with $W n t 8$ approximately at the boundary between the Fezf and IrxB domains. Interestingly, there is also a stripe of Engrailed in the general ectoderm that is in register with that in the CNS [193].

The tunicate C. intestinalis appears to have more of the ISO network in place than amphioxus does, but it has lost a key gene - Gbx. Pax 2/5/8 and Fgf8/17/18 are expressed in the neck region in a few cells just posterior to the posterior limit of Otx. Engrailed is expressed in two domains, one near the Pax2/5/8 domain and the other overlapping with that of Otx [194].

The emerging picture is that amphioxus has most, if not all of the genetic mechanism for the ANR in place and part of that for the ZLI and ISO while the ancestral tunicate probably added to these gene networks but subsequently lost parts of them as the CNS became simplified. The most parsimonious explanation is that the ancestral bilaterian had a CNS in which portions of these gene networks were used to establish divisions in the CNS and perhaps to some extent in the ectoderm generally, and these gene networks became modified in the protostome and deuterostome lineages. Under this scenario, the basic gene networks for specifying the ANR, ZLI and MHB began to be established in the ancestral chordate or even earlier in the ancestral deuterostome or ancestral bilaterian, and additional genes were recruited to these networks before tunicates branched off the lineage leading to vertebrates. In the tunicate lineage, in conjunction with shrinking genomes, a switch from regulative to determinate development and a reduction of cell numbers in the CNS, some parts of the ancestral tunicate networks for these brain regions were lost. Modifications occurring in the hemichordate lineage may have involved changes in the CNS and/or cooption of additional genes and portions of gene networks to the surface ectoderm. 


\section{Conclusions}

The bilaterian CNS typically develops from a longitudinal strip of ectoderm that is then internalized. Although the remainder of the ectoderm is usually termed "non-neural", it also contains numerous neurons - often sensory neurons - which send signals to the CNS. Therefore, the ectoderm really should be thought of as "more neural" and "less neural" rather than "neural" and "non-neural". This is highly relevant for discussion of how a CNS evolved from an ectodermal nerve net, since part of the genetic mechanism(s) for patterning the bilaterian CNS are shared with the ectoderm as a whole.

The basic A/P patterning mechanism in bilaterians with Six3/6 expressed anteriorly and Wnt genes posteriorly was inherited from an ancestral cnidarian-like animal. Additional genes (for example, Hox genes) were recruited to pattern the A/P axis of the ancestral bilaterian. Consequently, even though the ectoderm in annelids and arthropods is segmented, and the ectoderm of hemichordates and chordates is not, several genes that mediate A/P patterning of the $\mathrm{CNS}$ are expressed in similar patterns along the $\mathrm{A} / \mathrm{P}$ axis of the non-neural ectoderm in early embryos/larvae of both protostomes, chordates and hemichordates. For example, the patterns of Otx, Gbx and Hox genes in the early ectoderm of the annelid $P$. dumerilii are conserved in the neuroectoderm of amphioxus embryos with an anterior Otx domain abutting that of Gbx, anterior to nested domains of Hox expression [48]. Expression of $H o x$ genes and Gbx in the "non-neural ectoderm" in amphioxus is similar to that in the CNS $[131,134,192]$. In contrast, in the hemichordate ectoderm, while Otx and Gbx domains lie anterior to nested Hox domains, that of $G b x$ lies in between two domains of Otx [9].

More critical for distinguishing a CNS from the remainder of the ectoderm is the expression of the lateral/medial patterning genes ( $m s h / M s x$, ind/Gsh1, vnd/Nkx2.2), because expression of these genes is similar in the CNS of protostomes and chordates, but they are not expressed in comparable patterns in the "non-neural" ectoderm of either group.

The idea that the hemichordate ectoderm has organizing centers patterned by gene networks equivalent to those operating at the ANR, ZLI and ISO in the vertebrate CNS is based on similarities in gene expression as well as in some conserved gene interactions. However, some key genes involved in establishing these organizing centers in the vertebrate CNS are not similarly expressed in the hemichordate ectoderm. For example, in the $S$. kowalevskii ectoderm, the Fezf and Irx domains, which mark the vertebrate ZLI, do not abut at the collar/proboscis interface, while patterns of Otx and Wnt1 as well as those of $G b x$ and $F g f 8 / 17 / 18$, which mark the ISO, are reversed. Moreover, since parts of gene networks are often coopted for roles in different tissues, the fact that two genes interact does not suffice to demonstrate that a given region acts as an organizer. Thus, without transplantation experiments or at least the demonstration that a given morphogen such as $F g f 8 / 17 / 18$ can induce a change in cell fate when ectopically expressed, conclusions that homologs of these organizing centers are present in hemichordates are premature.

In addition, since several genes involved in specification of the ISO and ZLI are expressed in comparable positions in the amphioxus and vertebrate CNS as well as in the protostome CNS, claims that amphioxus has completely lost these regions are unwarranted. A more parsimonious explanation is that amphioxus has part of the machinery in place, upon which tunicates and vertebrates elaborated. Tunicates do appear to have more of the genetic machinery for specification of the ISO than amphioxus does, but have lost some key components, such as the $G b x$ gene.

The Ambulacraria (hemichordates and echinoderms), which are the sister group to chordates in the deuterostomes, are interesting in regard to what evolution can do. Both hemichordates and echinoderms have ectodermal nerve nets plus nerve cords. Gene expression indicates that the nerve cords of echinoderms, which have evolved pentamerous symmetry, are probably not homologous to chordate or protostome nerve cords. Hox genes, for example, are expressed in the developing coeloms of the adult, but not in the nerve cords or ectoderm $[48,51]$. It has been suggested that one or the other nerve cord of hemichordates is evolutionarily related to the chordate CNS, with historical opinions generally favoring the dorsal cord. However, dorsal expression of $B M P s$ suggests that this homolog would be the ventral nerve cord even though it is the dorsal nerve cord that neurulates. If this is true, then a $\mathrm{D} / \mathrm{V}$ inversion would have occurred at the base of the chordate lineage.

In sum, similar expression patterns of developmental genes involved in both $\mathrm{A} / \mathrm{P}$ and $\mathrm{D} / \mathrm{V}$ patterning in the protostome and chordate nerve cords as well as anatomical and functional similarities support the view that the ancestral bilaterian had a CNS. In the Ambulacraria, echinoderms may have lost this CNS, while it remains to be seen whether either of the hemichordate nerve cords is homologous to that of protostomes and chordates. Similarities of gene expression in the hemichordate ectoderm and chordate CNS may reflect conservation of $\mathrm{A} / \mathrm{P}$ patterning in the ectoderm as a whole and in the CNS of bilaterians and/or a merging of the anterior portion of the brain and the proboscis ectoderm during evolution of hemichordates. A comprehensive study of expression of developmental genes in the hemichordate nerve cords would help to resolve these questions. In any event, similarities in gene expression between the CNS of amphioxus and vertebrates indicate that amphioxus has 
at least part of the genetic mechanisms for the ANR, ZLI and MHB in place and suggest that vertebrates subsequently elaborated upon these gene networks.

\section{Abbreviations}

ANR: Anterior neural ridge; A/P: Anterior/posterior; BMP: Bone

morphogenetic protein; CNS: Central nervous system; DN: Dorso/ventral; ISO: Isthmic organizer; MHB: Midbrain/hindbrain boundary; ZLI: Zona limitans intrathalamica.

\section{Competing interests}

The authors declare that they have no competing interests.

\section{Authors' contributions}

LZH coordinated and wrote much of the manuscript. MS, HE, SMS, JKY and VL contributed to writing the manuscript. JEC and MS prepared the figures. All authors read and approved the final manuscript.

\section{Acknowledgements}

The authors thank Peter WH Holland, ND Holland and Nacho Maeso for critically reading the manuscript and for useful suggestions. JKY was supported by the National Science Council, Taiwan (NSC99-2627-B-001-003, NSC101-2923-B-001-004-MY2), and by the Career Development Award from Academia Sinica, Taiwan (AS-98-CDA-L06). MS was supported by funds from the ANR (ANR-09-BLAN-0262-02 and ANR-11-JSV2-002-01), CNRS and UPMC

\section{Author details}

${ }^{1}$ Marine Biology Research Division, Scripps Institution of Oceanography, University of California at San Diego, La Jolla, CA 92093-0202, USA. ${ }^{2}$ Laboratoire de Biologie du Développement de Villefranche-sur-Mer (UMR 7009 - CNRS/UPMC), Observatoire Océanologique de Villefranche-sur-Mer, 181 Chemin du Lazaret, B.P. 28, 06230 Villefranche-sur-Mer, France. ${ }^{3} \mathrm{CNRS}$, UMR 7232, BIOM, Université Pierre et Marie Curie Paris 06, Observatoire Océanologique, 66650 Banyuls-sur-Mer, France. ${ }^{4}$ Institut de Génomique Fonctionnelle de Lyon (CNRS UMR5242, UCBL, ENS, INRA 1288), Ecole Normale Supérieure de Lyon, 46 allée d'Italie, 69364 Lyon Cedex 07, France. ${ }^{5}$ Department of Zoology, University of Oxford, The Tinbergen Building, South Parks Road, Oxford OX1 3PS, UK. ${ }^{\text {In }}$ stitute of Cellular and Organismic Biology, Academia Sinica, Taipei 11529, Taiwan.

\section{Received: 8 April 2013 Accepted: 14 August 2013}

Published: 7 October 2013

\section{References}

1. Arendt $D$, Denes $A S$, Jékely $G$, Tessmar-Raible $K$ : The evolution of nervous system centralization. Philos Trans R Soc Lond B Biol Sci 2008, 363:1523-1528.

2. Tomer R, Denes AS, Tessmar-Raible K, Arendt D: Profiling by image registration reveals common origin of annelid mushroom bodies and vertebrate pallium. Cell 2010, 142:800-809.

3. Strausfeld NJ, Hirth F: Deep homology of arthropod central complex and vertebrate basal ganglia. Science 2013, 340:157-161.

4. Strausfeld NJ: Brain homology: Dohrn of a new era? Brain Behav Evol 2010, 76:165-167.

5. Hirth F, Kammermeier L, Frei E, Walldorf U, Noll M, Reichert H: An urbilaterian origin of the tripartite brain: developmental genetic insights from Drosophila. Development 2003, 130:2365-2373.

6. Sen S, Reichert H, VijayRaghavan $\mathrm{K}$ : Conserved roles of ems/Emx and otd/ Otx genes in olfactory and visual system development in Drosophila and mouse. Open Biol 2013, 3:120177.

7. Bailly $X$, Reichert $H$, Hartenstein $V$ : The urbilaterian brain revisited: novel insights into old questions from new flatworm clades. Dev Genes Evol 2013, 223:149-157.

8. De Robertis EM: The molecular ancestry of segmentation mechanisms. Proc Natl Acad Sci U S A 2008, 105:16411-16412.

9. Pani AM, Mullarkey EE, Aronowicz J, Assimacopoulos S, Grove EA, Lowe CJ: Ancient deuterostome origins of vertebrate brain signalling centres. Nature 2012, 483:289-294.

10. Gerhart J, Lowe C, Kirschner M: Hemichordates and the origin of chordates. Curr Opin Genet Dev 2005, 15:461-467.
11. Wagner GP: The biological homology concept. Annu Rev Ecol Sys 1989, 20:51-69.

12. Cracraft J: Phylogeny and evo-devo: characters, homology, and the historical analysis of the evolution of development. Zoology 2005, 108:345-356.

13. Richter S: Homologies in phylogenetic analyses - concept and tests. Theory Biosci 2005, 124:105-120.

14. Jenner RA: Unburdening evo-devo: ancestral attractions, model organisms, and basal baloney. Dev Genes Evol 2006, 216:385-394.

15. Ghiselin MT: The nomenclature of correspondence: a new look at 'homology' and 'analogy'. In Evolution, Brain and Behavior: Persistent Problems. 2nd edition. Edited by Masterton RB, Hodos W, Jerison H. New York: Wiley; 1976.

16. Wagner GP: The developmental genetics of homology. Nat Rev Genet 2007, 8:473-479.

17. Hodos W: The concept of homology and the evolution of behavior. In Evolution, Brain and Behavior: Persistent Problems. Volume 2. Edited by Masterton RB, Hodos W, Jerison H. New York: Wiley; 1976.

18. Remane A: Methodological problems of hominid phylogeny. 3. Phylogeny of lifestyles and the origin of upright gait. $Z$ Morphol Anthropol 1956, 48:28-54.

19. Haeckel E: The gastraea-theory, the phylogenetic classification of the animal kindgom and the homology of the germ-lamellae. Q J Microsc Sci 1874, 14:142-165. 223-247.

20. Striedter GF, Northcutt RG: Biological hierarchies and the concept of homology. Brain Behav Evol 1991, 38:177-189.

21. Bolker JA, Raff RA: Developmental genetics and traditional homology. Bioessays 1996, 18:489-494.

22. Sasai Y, Lu B, Steinbeisser H, De Robertis EM: Regulation of neural induction by the Chd and Bmp-4 antagonistic patterning signals Xenopus in. Nature 1995, 376:333-336.

23. De Robertis EM: Evo-devo: variations on ancestral themes. Cell 2008, 132:185-195.

24. Lowe CJ, Wu M, Salic A, Evans L, Lander E, Stange-Thomann N, Gruber CE, Gerhart J, Kirschner M: Anteroposterior patterning in hemichordates and the origins of the chordate nervous system. Cell 2003, 113:853-865.

25. Aronowicz J, Lowe CJ: Hox gene expression in the hemichordate Saccoglossus kowalevskii and the evolution of deuterostome nervous systems. Integr Comp Biol 2006, 46:890-901.

26. Hejnol A, Martindale MQ: Acoel development indicates the independent evolution of the bilaterian mouth and anus. Nature 2008, 456:382-386.

27. Gerhart J: Inversion of the chordate body axis: are there alternatives? Proc Natl Acad Sci U S A 2000, 97:4445-4448.

28. Gerhart J: The deuterostome ancestor. J Cell Physiology 2006, 209:677-685

29. Sprecher SG, Reichert H: The urbilaterian brain: developmental insights into the evolutionary origin of the brain in insects and vertebrates. Arthropod Struct Dev 2003, 32:141-156.

30. Martindale Mark Q: Evolution of development: the details are in the entrails. Curr Biol 2013, 23:R25-R28.

31. Northcutt RG: Evolution of centralized nervous systems: two schools of evolutionary thought. Proc Natl Acad Sci USA 2012, 109(Suppl 1):10626-10633.

32. Koizumi O, Sato N, Goto C: Chemical anatomy of hydra nervous system using antibodies against hydra neuropeptides: a review. Hydrobiologia 2004, 530-531:41-47.

33. Haag ES: Echinoderm rudiments, rudimentary bilaterians, and the origin of the chordate CNS. Evol Dev 2005, 7:280-281.

34. Holland ND: Early central nervous system evolution: an era of skin brains? Nat Rev Neurosci 2003, 4:617-627.

35. Philippe H, Brinkmann H, Copley RR, Moroz LL, Nakano H, Poustka AJ, Wallberg A, Peterson KJ, Telford MJ: Acoelomorph flatworms are deuterostomes related to Xenoturbella. Nature 2011, 470:255-258.

36. Hejnol A, Obst M, Stamatakis A, Ott M, Rouse GW, Edgecombe GD, Martinez P, Baguñà J, Bailly X, Jondelius U, Wiens M, Müller WE, Seaver E, Wheeler WC, Martindale MQ, Giribet G, Dunn CW: Assessing the root of bilaterian animals with scalable phylogenomic methods. Proc Roy Soc B: Biol Sci 2009, 276:4261-4270.

37. Bery A, Cardona A, Martinez P, Hartenstein V: Structure of the central nervous system of a juvenile acoel, Symsagittifera roscoffensis. Dev Genes Evol 2010, 220:61-76. 
38. Raikova OI, Reuter M, Jondelius U, Gustafsson MKS: An immunocytochemical and ultrastructural study of the nervous and muscular systems of Xenoturbella westbladi (Bilateria inc. sed.). Zoomorphology 2000, 120:107-118.

39. Sinigaglia C, Busengdal $H$, Leclère $L$, Technau U, Rentzsch F: The bilaterian head patterning gene six $3 / 6$ controls aboral domain development in a cnidarian. PLOS Biol 2013, 11:e1001488.

40. Yaguchi S, Yaguchi J, Angerer RC, Angerer LM: A Wnt-FoxQ2-Nodal pathway links primary and secondary axis specification in sea urchin embryos. Dev Cell 2008, 14:97-107.

41. Yu J-K, Holland N, Holland L: AmphiFoxQ2, a novel winged helix/forkhead gene, exclusively marks the anterior end of the amphioxus embryo. Dev Genes Evol 2003, 213:102-105.

42. Steinmetz PR, Urbach R, Posnien N, Eriksson J, Kostyuchenko RP, Brena C Guy K, Akam M, Bucher G, Arendt D: Six3 demarcates the anterior-most developing brain region in bilaterian animals. EvoDevo 2010, 1:14

43. Kozmik Z, Holland ND, Kreslova J, Oliveri D, Schubert M, Jonasova K, Holland LZ, Pestarino M, Benes V, Candiani S: Pax-Six-Eya-Dach network during amphioxus development: conservation in vitro but context specificity in vivo. Dev Biol 2007, 306:143-159.

44. Santagata S, Resh C, Hejnol A, Martindale MQ, Passamaneck YJ: Development of the larval anterior neurogenic domains of Terebratalia transversa (Brachiopoda) provides insights into the diversification of larval apical organs and the spiralian nervous system. EvoDevo 2012, 3:3.

45. Hirth $\mathrm{F}$, Reichert $\mathrm{H}$ : Conserved genetic programs in insect and mammalian brain development. BioEssays 1999, 21:677-684.

46. Lichtneckert $\mathrm{R}$, Reichert $\mathrm{H}$ : Anteroposterior regionalization of the brain: genetic and comparative aspects. Adv Exp Med Biol 2008, 628:32-41.

47. Sasakura Y, Mita K, Ogura Y, Horie T: Ascidians as excellent chordate models for studying the development of the nervous system during embryogenesis and metamorphosis. Dev Growth Differ 2012, 54:420-437.

48. Steinmetz PRH, Kostyuchenko RP, Fischer A, Arendt D: The segmental pattern of $o t x, g b x$, and Hox genes in the annelid Platynereis dumerilii. Evol Dev 2011, 13:72-79.

49. Lee PN, Callaerts P, de Couet HG, Martindale MQ: Cephalopod Hox genes and the origin of morphological novelties. Nature 2003, 424:1061-1065.

50. Tihanyi BVT, Regos A, Ari E, Müller F, Takács-Vellai K: The C. elegans Hox gene ceh-13 regulates cell migration and fusion in a non-colinear way. Implications for the early evolution of Hox clusters. BMC Dev Biol 2010, 10:78

51. Arenas-Mena C, Cameron AR, Davidson EH: Spatial expression of Hox cluster genes in the ontogeny of a sea urchin. Development 2000, 127:4631-4643.

52. Barak H, Preger-Ben Noon E, Reshef R: Comparative spatiotemporal analysis of Hox gene expression in early stages of intermediate mesoderm formation. Dev Dynam 2012, 241:1637-1649.

53. Hara Y, Yamaquchi M, Akasaka K, Nakano H, Nonaka M, Amemiya S: Expression patterns of Hox genes in larvae of the sea lily Metacrinus rotundus. Dev Genes Evol 2006, 216:797-809.

54. Seo H-C, Edvardsen RB, Maeland AD, Bjordal M, Jensen MF, Hansen A, Flaat M, Weissenbach J, Lehrach H, Wincker P, Reinhardt R, Chourrout D: Hox cluster disintegration with persistent anteroposterior order of expression in Oikopleura dioica. Nature 2004, 431:67-71.

55. Galliot B, Quiquand M, Ghila L, de Rosa R, Miljkovic-Licina M, Chera S: Origins of neurogenesis, a cnidarian view. Dev Biol 2009, 332:2-24

56. Ryan JF, Mazza ME, Pang K, Matus DQ, Baxevanis AD, Martindale MQ Finnerty JR: Pre-bilaterian origins of the Hox cluster and the Hox code: evidence from the sea anemone. Nematostella vectensis. PLOS ONE 2007, 2:e153.

57. de Rosa R, Grenier JK, Andreeva T, Cook CE, Adoutte A, Akam M, Carroll SB, Balavoine G: Hox genes in brachiopods and priapulids and protostome evolution. Nature 1999, 399:772-776.

58. Hejnol A, Martindale MQ: Coordinated spatial and temporal expression of Hox genes during embryogenesis in the acoel Convolutriloba longifissura. BMC Biol 2009, 7:65.

59. Moreno E, Nadal M, Baguna J, Martinez P: Tracking the origins of the bilaterian Hox patterning system: insights from the acoel flatworm Symsagittifera roscoffensis. Evol Dev 2009, 11:574-581.

60. Reichert $\mathrm{H}$ : A tripartite organization of the urbilaterian brain: developmental genetic evidence from drosophila. Brain Res Bull 2005, 66:491-494
61. Inoue F, Kurokawa D, Takahashi M, Aizawa S: Gbx2 directly restricts Otx2 expression to forebrain and midbrain, competing with Class III POU factors. Mol Cell Biol 2012, 32:2618-2627.

62. Püschel AW, Westerfield M, Dressler GR: Comparative analysis of Pax-2 protein distributions during neurulation in mice and zebrafish. Mech Dev 1992, 38:197-208.

63. Pfeiffer BD, Jenett A, Hammonds AS, Ngo T-TB, Misra S, Murphy C, Scully A, Carlson JW, Wan KH, Laverty TR, Mungall C, Svirskas R, Kadonaga JT, Doe $\mathrm{CQ}$, Eisen MB, Celniker SE, Rubin GM: Tools for neuroanatomy and neurogenetics in Drosophila. Proc Natl Acad Sci U S A 2008, 105:9715-9720.

64. Irimia M, Piñeiro C, Maeso I, Gómez-Skarmeta JL, Casares F, Garcia-Fern àndez J: Conserved developmental expression of Fezf in chordates and Drosophila and the origin of the Zona Limitans Intrathalamica (ZLI) brain organizer. EvoDevo 2010, 1:7.

65. Hirata T, Nakazawa M, Muraoka O, Nakayama R, Suda Y, Hibi M: Zinc-finger genes Fez and Fez-like function in the establishment of diencephalon subdivisions. Development 2006, 133:3993-4004.

66. Mizutani CM, Bier E: EvoD/No: the origins of BMP signalling in the neuroectoderm. Nat Rev Genet 2008, 9:663-677.

67. Urbach R, Technau GM: Dorsoventral patterning of the brain: a comparative approach. In, Volume 628 Edited by Technau GM. New York: Springer; 2008:42-56.

68. Holland LZ: Chordate roots of the vertebrate nervous system: expanding the molecular toolkit. Nat Rev Neurosci 2009, 10:736-746.

69. Vopalensky P, Pergner J, Liegertova M, Benito-Gutierrez E, Arendt D, Kozmik Z: Molecular analysis of the amphioxus frontal eye unravels the evolutionary origin of the retina and pigment cells of the vertebrate eye. Proc Natl Acad Sci U S A 2012, 109:15383-15388.

70. Holland ND, Panganiban G, Henyey EL, Holland LZ: Sequence and developmental expression of AmphiDll, an amphioxus Distal-less gene transcribed in the ectoderm, epidermis and nervous system: insights into evolution of craniate forebrain and neural crest. Development 1996 122:2911-2920.

71. Shimeld SM, van den Heuvel M, Dawber R, Briscoe J: An amphioxus Gli gene reveals conservation of midline patterning and the evolution of Hedgehog signalling diversity in chordates. PLOS ONE 2007, 2:e864.

72. Robertshaw E, Kiecker C: Phylogenetic origins of brain organisers. Scientifica 2012, 2012:1-14.

73. Seimiya M, Gehring WJ: The Drosophila homeobox gene optix is capable of inducing ectopic eyes by an eyeless-independent mechanism. Development 2000, 127:1879-1886.

74. Beccari L, Marco-Ferreres R, Bovolenta P: The logic of gene regulatory networks in early vertebrate forebrain patterning. Mech Dev 2013, 130:95-111.

75. Mazet F, Hutt JA, Millard J, Shimeld SM: Pax gene expression in the developing central nervous system of Ciona intestinalis. Gene Exp Patt 2003, 3:743-745

76. D'Aniello S, D'Aniello E, Locascio A, Memoli A, Corrado M, Russo MT, Aniello F, Fucci L, Brown ER, Branno M: The ascidian homolog of the vertebrate homeobox gene $R x$ is essential for ocellus development and function. Differentiation 2006, 74:222-234.

77. Caracciolo A, Di Gregorio A, Aniello F, Di Lauro R, Branno M: Identification and developmental expression of three Distal-less homeobox containing genes in the ascidian Ciona intestinalis. Mech Dev 2000, 99:173-176.

78. Imai KS, Satoh N, Satou Y: Region specific gene expressions in the central nervous system of the ascidian embryo. Mech Dev 2002, 119(Suppl):S275-S277.

79. Islam AFMT, Moly PK, Miyamoto Y, Kusakabe TG: Distinctive expression patterns of Hedgehog pathway genes in the Ciona intestinalis larva: implications for a role of Hedgehog signaling in postembryonic development and chordate evolution. Zoolog Sci 2010, 27:84-90

80. Retaux S, Kano S: Midline signaling and evolution of the forebrain in chordates: a focus on the lamprey hedgehog case. Integr Comp Biol 2010, 50:98-109.

81. Denes AS, Jékely G, Steinmetz PRH, Raible F, Snyman H, Prud'homme B, Ferrier DEK, Balavoine G, Arendt D: Molecular architecture of annelid nerve cord supports common origin of nervous system centralization in Bilateria. Cell 2007, 129:277-288.

82. Heuer CM, Mueller CHG, Todt C, Loesel R: Comparative neuroanatomy suggests repeated reduction of neuroarchitectural complexity in Annelida. Front Zool 2010, 7:13 
83. Sikes $\mathrm{JM}$, Bely AE: Making heads from tails: development of a reversed anterior-posterior axis during budding in an acoel. Dev Biol 2010, 338:86-97.

84. Achatz JG, Martinez P: The nervous system of Isodiametra pulchra (Acoela) with a discussion on the neuroanatomy of the Xenacoelomorpha and its evolutionary implications. Front Zool 2012, 9:27.

85. Lacalli TC: Protochordate body plan and the evolutionary role of larvae: old controversies resolved? Can J Zool 2005, 83:216-224.

86. Dohrn A: Der Ursprung der Wirbelthiere und das Princip des Functionswechsels. Leipzig: Wilhelm Englmann; 1875.

87. Van-Wijhe JW: Die Terminalbeuge des Vorderhirns bei den Chordaten und die prootischen Nerven der Kranioten bei Amphioxus. Erste Mitteilung plus Zweite Mitteilung: Schluss des Riechorgans. Proc Koninklijke Akademie Van Wetenschappen Te Amsterdam 1931, 34:131-141. (Erste Mitteilung); \& 636-653 (Zweite Mitteilung).

88. Nomaksteinsky M, Röttinger E, Dufour HD, Chettouh Z, Lowe CJ, Martindale $\mathrm{MQ}$, Brunet J-F: Centralization of the deuterostome nervous system predates chordates. Curr Biol 2009, 19:1264-1269.

89. De Robertis EM, Sasai Y: A common plan for dorsoventral patterning in Bilateria. Nature 1996, 380:37-40.

90. Duboc V, Röttinger E, Lapraz F, Besnardeau L, Lepage T: Left-right asymmetry in the sea urchin embryo is regulated by Nodal signaling on the right side. Dev Cell 2005, 9:147-158.

91. Grande C, Patel NH: Nodal signalling is involved in left-right asymmetry in snails. Nature 2009, 457:1007-1011.

92. Nielsen C: Homology of echinoderm radial nerve cords and the chordate neural tube? Evol Dev 2006, 8:1-2.

93. Sly BJ, Hazel JC, Popodi EM, Raff RA: Patterns of gene expression in the developing adult sea urchin central nervous system reveal multiple domains and deep-seated neural pentamery. Evol Dev 2002, 4:189-204.

94. Cisternas P, Byrne M: Expression of Hox4 during development of the pentamerous juvenile sea star, Parvulastra exigua. Dev Genes Evol 2009, 219:613-618.

95. Morris VB, Byrne M: Involvement of two Hox genes and Otx in echinoderm body-plan morphogenesis in the sea urchin Holopneustes purpurescens. J Exp Zool Part B: Mol Dev Evol 2005, 304B:456-467.

96. Lacalli TC: Head organization and the head/trunk relationship in protochordates: problems and prospects. Integr Comp Bio/ 2008, 48:620-629.

97. Nieuwenhuys R: Deuterostome brains: synopsis and commentary. Brain Res Bull 2002, 57:257-270.

98. Tagawa K, Humphreys T, Satoh N: T-brain expression in the apical organ of hemichordate tornaria larvae suggests its evolutionary link to the vertebrate forebrain. J Exp Zool 2000, 288:23-31.

99. Stach T, Gruhl A, Kaul-Strehlow S: The central and peripheral nervous system of Cephalodiscus gracilis (Pterobranchia, Deuterostomia). Zoomorphology 2012, 131:11-24.

100. Romer AS: Major steps in vertebrate evolution. Science 1967, 158:1629-1637

101. Williams JB: Sessile lifestyle and origin of chordates. New Zealand J Zool 1996, 23:111-133.

102. Osborn KJ, Kuhnz LA, Priede IG, Urata M, Gebruk AV, Holland ND: Diversification of acorn worms (Hemichordata, Enteropneusta) revealed in the deep sea. Proc Roy Soc B: Biol Sci 2012, 279:1646-1654.

103. Cannon JT, Rychel AL, Eccleston H, Halanych KM, Swalla BJ: Molecular phylogeny of hemichordata, with updated status of deep-sea enteropneusts. Mol Phylog Evol 2009, 52:17-24.

104. Caron J-B, Morris SC, Cameron CB: Tubicolous enteropneusts from the Cambrian period. Nature 2013, 495:503-506.

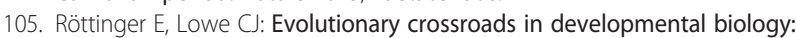
hemichordates. Development 2012, 139:2463-2475.

106. Miyamoto N, Nakajima Y, Wada H, Saito Y: Development of the nervous system in the acorn worm Balanoglossus simodensis: insights into nervous system evolution. Evol Dev 2010, 12:416-424.

107. Kaul S, Stach T: Ontogeny of the collar cord: neurulation in the hemichordate Saccoglossus kowalevskii. J Morph 2010, 271:1240-1259.

108. Bateson W: The later stages in the development of Balanoglossus kowalevskii, with a suggestion as to the affinities of the Enteropneusta. Q J Microsc Sci 1886, 126:511-533.

109. Rehkämper G, Welsch U, Dilly PN: Fine structure of the ganglion of Cephalodiscus gracilis (Pterobranchia, Hemichordata). J Comp Neurol 1987, 259:308-315.
110. Brown FD, Prendergast A, Swalla BJ: Man is but a worm: chordate origins. Genesis 2008, 46:605-613.

111. Bullock TH: The giant nerve fiber system in balanoglossids. J Comp Neurol 1944, 80:355-367.

112. Nielsen C, Hay-Schmidt A: Development of the enteropneust Ptychodera flava: ciliary bands and nervous system. J Morph 2007, 268:551-570.

113. Lowe CJ, Terasaki M, Wu M, Freeman RM Jr, Runft L, Kwan K, Haigo S, Aronowicz J, Lander E, Gruber C, Smith M, Kirschner M, Gerhart J: Dorsoventral patterning in hemichordates: Insights into early chordate evolution. PLOS Biol 2006, 4:e291.

114. Taguchi S, Tagawa K, Humphreys T, Satoh N: Group B Sox genes that contribute to specification of the vertebrate brain are expressed in the apical organ and ciliary bands of hemichordate larvae. Zool Sci 2002, 19:57-66.

115. Tagawa K, Satoh N, Humphreys T: Molecular studies of hemichordate development: a key to understanding the evolution of bilateral animals and chordates. Evol Dev 2001, 3:443-454.

116. Peterson KJ, Cameron RA, Tagawa K, Satoh N, Davidson EH: A comparative molecular approach to mesodermal patterning in basal deuterostomes: the expression pattern of Brachyury in the enteropneust hemichordate Ptychodera flava. Development 1999, 126:85-95.

117. Onai T, Yu J-K, Blitz IL, Cho KWY, Holland LZ: Opposing Nodal/Vg1 and BMP signals mediate axial patterning in embryos of the basal chordate amphioxus. Dev Biol 2010, 344:377-389.

118. Wlizla M: Evolution of Nodal signaling in deuterostomes: insights from Saccoglossus kowalevskii. PhD dissertation. University of Chicago. 2011:195.

119. Saudemont A, Haillot E, Mekpoh F, Bessodes N, Quirin M, Lapraz F, Duboc V, Röttinger E, Range R, Oisel A, Besnardeau L, Wincker P, Lepage T: Ancestral regulatory circuits governing ectoderm patterning downstream of Nodal and BMP2/4 revealed by gene regulatory network analysis in an echinoderm. PLoS Genet 2010, 6:e1001259.

120. Grande C, Patel NH: Lophotrochozoa get into the game: the nodal pathway and left/right asymmetry in Bilateria. Cold Spring Harb Symp Quant Biol 2009, 74:281-287.

121. de Beer G: Homology, An Unsolved Problem, Volume 11. Oxford: Oxford University Press; 1971.

122. Roth VL: The biological basis of homology. In Ontogeny and Systematics. Edited by Humphries CJ. New York: Columbia University Press; 1988.

123. Panganiban G, Irvine SM, Lowe CJ, Roehl HH, Corley LS, Sherbon B, Grenier JK, Fallon JF, Kimble J, Walker M, Wray GA, Swalla BJ, Martindale MQ, Carroll SB: The origin and evolution of animal appendages. Proc Natl Acad SCl USA 1997, 94:5162-5166.

124. Northcutt RG: Changing views of brain evolution. Brain Res Bull 2001 55:663-674.

125. Shubin N, Tabin C, Carroll SB: Deep homology and the origins of evolutionary novelty. Nature 2009, 457:818-823.

126. Lowe $\mathrm{CJ}$ : Molecular genetic insights into deuterostome evolution from the direct-developing hemichordate Saccoglossus kowalevskii. Philos Trans R Soc Lond B Biol Sci 2008, 363:1569-1578.

127. Stokes MD, Holland ND: Embryos and larvae of a lancelet, Branchiostoma floridae, from hatching through metamorphosis: growth in the laboratory and external morphology. Acta Zool 1995, 76:105-120.

128. Bone Q, Ryan KP: Cupular sense organs in Ciona (Tunicata: Ascidiacea). J Zool, London 1978, 186:417-429.

129. Wood HB, Episkopou V: Comparative expression of the mouse Sox1, Sox2 and Sox3 genes from pre-gastrulation to early somite stages. Mech Dev 1999, 86:197-201.

130. Satoh G, Wang Y, Zhang P, Satoh N: Early development of amphioxus nervous system with special reference to segmental cell organization and putative sensory cell precursors: a study based on the expression of pan-neuronal marker gene Hulelav. J Exp Zool 2001, 291:354-364.

131. Ghost Database. [http://ghost.zool.kyoto-u.ac.jp/SearchGenomekh.html]

132. Schubert $M$, Holland ND, Escriva $H$, Holland LZ, Laudet V: Retinoic acid influences anteroposterior positioning of epidermal sensory neurons and their gene expression in a developing chordate (amphioxus). Proc Natl Acad Sci U S A 2004, 101:10320-10325.

133. Sasakura Y, Kanda M, Ikeda T, Horie T, Kawai N, Ogura Y, Yoshida R, Hozum A, Satoh N, Fujiwara S: Retinoic acid-driven Hox 1 is required in the epidermis for forming the otic/atrial placodes during ascidian metamorphosis. Development 2012, 139:2156-2160. 
134. Watari-Goshima N, Chisaka O: Chicken HOXA3 gene: its expression pattern and role in branchial nerve precursor cell migration. Int J Biol Sci 2011, 7:87-101.

135. Castro LFC, Rasmussen SLK, Holland PWH, Holland ND, Holland LZ: A Gbx homeobox gene in amphioxus: insights into ancestry of the ANTP class and evolution of the midbrain/hindbrain boundary. Dev Biol 2006 295:40-51.

136. Sánchez-Calderón H, Martín-Partido G, Hidalgo-Sánchez M: Differential expression of Otx2, Gbx2, Pax2, and Fgf8 in the developing vestibular and auditory sensory organs. Brain Res Bull 2002, 57:321-323.

137. Steventon B, Mayor R, Streit A: Mutual repression between Gbx2 and Otx2 in sensory placodes reveals a general mechanism for ectodermal patterning. Dev Biol 2012, 367:55-65.

138. Sharman AC, Shimeld SM, Holland PWH: An amphioxus Msx gene expressed predominantly in the dorsal neural tube. Dev Genes Evol 1999, 209:260-263.

139. Osborne PW, Benoit G, Laudet V, Schubert M, Ferrier DE: Differentia regulation of ParaHox genes by retinoic acid in the invertebrate chordate amphioxus (Branchiostoma floridae). Dev Biol 2009, 327:252-262.

140. Venkatesh TV, Holland ND, Holland LZ, Su M-T, Bodmer R: Sequence and developmental expression of amphioxus AmphiNk2-1: insights into the evolutionary origin of the vertebrate thyroid gland and forebrain. Dev Genes Evol 1999, 209:254-259.

141. Kawashima T, Murakami AR, Ogasawara M, Tanaka K, Isoda R, Sasakura Y, Nishikata T, Okano H, Makabe KW: Expression patterns of musashi homologs of the ascidians, Halocynthia roretzi and Ciona intestinalis. Dev Genes Evol 2000, 210:162-165.

142. Wada S, Tokuoka M, Shoguchi E, Kobayashi K, Di Gregorio A, Spagnuolo A Branno M, Kohara Y, Rokhsar D, Levine M, Saiga H, Satoh N, Satou Y: A genomewide survey of developmentally relevant genes in Ciona intestinalis. II. Genes for homeobox transcription factors. Dev Genes Evol 2003, 213:222-234.

143. Ghanbari H, Seo H-C, Fjose A, Brändli AW: Molecular cloning and embryonic expression of Xenopus Six homeobox genes. Mech Dev 2001, 101:271-277.

144. Osorio J, Mazan S, Rétaux S: Organisation of the lamprey (Lampetra fluviatilis) embryonic brain: insights from LIM-homeodomain, Pax and hedgehog genes. Dev Biol 2005, 288:100-112.

145. Toresson H, Martinez-Barbera JP, Bardsley A, Caubit X, Krauss S: Conservation of $B F-1$ expression in amphioxus and zebrafish suggests evolutionary ancestry of anterior cell types that contribute to the vertebrate telencephalon. Dev Genes Evol 1998, 208:431-439.

146. Hatini $V$, Ye X, Balas G, Lai E: Dynamics of placodal lineage development revealed by targeted transgene expression. Dev Dynam 1999, 215:332-343.

147. Kaltenbach SL, Yu J-K, Holland ND: The origin and migration of the earliest-developing sensory neurons in the peripheral nervous system of amphioxus. Evol Dev 2009, 11:142-151.

148. Logan C, Wingate RJ, McKay IJ, Lumsden A: T/x-1 and T/x-3 homeobox gene expression in cranial sensory ganglia and hindbrain of the chick embryo: markers of patterned connectivity. J Neurosci 1998, 18:5389-5402.

149. Chellappa R, Li S, Pauley S, Jahan I, Jin K, Xiang M: Barh/1 regulatory sequences required for cell-specific gene expression and autoregulation in the inner ear and central nervous system. Mol Cell Biol 2008, 28:1905-1914.

150. Kawahara A, Dawid IB: Developmental expression of zebrafish emx1 during early embryogenesis. Gene Exp Patt 2002, 2:201-206.

151. Bardet SM, Martinez-de-la-Torre M, Northcutt RG, Rubenstein JLR, Puelles L: Conserved pattern of OTP-positive cells in the paraventricular nucleus and other hypothalamic sites of tetrapods. Brain Res Bull 2008, 75:231-235

152. Ma P, Zhao S, Zeng W, Yang Q, Li C, Lv X, Zhou Q, Mao B: Xenopus Dbx2 is involved in primary neurogenesis and early neural plate patterning Biochem Biophy Res Com 2011, 412:170-174.

153. Langeland JA, Holland LZ, Chastain RA, Holland ND: An amphioxus LIMhomeobox gene, AmphiLim1/5, expressed early in the invaginating organizer region and later in differentiating cells of the kidney and central nervous system. Int J Biol Sci 2006, 2:110-116.

154. Feijóo CG, Saldias MP, De la Paz JF, Gómez-Skarmeta JL, Allende ML: Formation of posterior cranial placode derivatives requires the Iroquois transcription factor irx4a. Mol Cell Neurosci 2009, 40:328-337.
155. Matsuura M, Nishihara H, Onimaru K, Kokubo N, Kuraku S, Kusakabe R, Okada N, Kuratani S, Tanaka M: Identification of four Engrailed genes in the Japanese lamprey, Lethenteron japonicum. Dev Dyn 2008, 237:1581-1589.

156. Ikuta T, Yoshida N, Satoh N, Saiga H: Ciona intestinalis Hox gene cluster: its dispersed structure and residual colinear expression in development. Proc Natl Acad Sci U S A 2004, 101:15118-15123.

157. Makki N, Capecchi MR: Hoxa1 lineage tracing indicates a direct role for Hoxa1 in the development of the inner ear, the heart, and the third rhombomere. Dev Biol 2010, 341:499-509.

158. Takio Y, Kuraku S, Murakami Y, Pasqualetti M, Rijli FM, Narita Y, Kuratani S, Kusakabe R: Hox gene expression patterns in Lethenteron japonicum embryos - insights into the evolution of the vertebrate Hox code. Dev Biol 2007, 308:606-620.

159. Uchiyama K, Otsuka R, Hanaoka K: CHox11L2, a Hox 11 related gene, is expressed in the peripheral nervous system and subpopulation of the spinal cord during chick development. Neurosci Lett 1999, 273:97-100.

160. Sanchez-Arrones L, Stern CD, Bovolenta P, Puelles L: Sharpening of the anterior neural border in the chick by rostral endoderm signalling. Development 2012, 139:1034-1044.

161. Tendeng $C$, Houart $C$ : Cloning and embryonic expression of five distinct sfrp genes in the zebrafish Danio rerio. Gene Expr Patterns 2006, 6:761-771.

162. Eagleson GW, Dempewolf RD: The role of the anterior neural ridge and Fgf-8 in early forebrain patterning and regionalization in Xenopus laevis. Comp Biochem Physiol B Biochem Mol Biol 2002, 132:179-189.

163. Vieira C, Martinez S: Sonic hedgehog from the basal plate and the zona limitans intrathalamica exhibits differential activity on diencephalic molecular regionalization and nuclear structure. Neuroscience 2006, 143:129-140.

164. Green SA, Norris RP, Terasaki M, Lowe CJ: FGF signaling induces mesoderm in the hemichordate Saccoglossus kowalevskii. Development 2013, 140:1024-1033.

165. Holland ND, Holland LZ: Amphioxus and the utility of molecular genetic data for hypothesizing body part homologies between distantly related animals. Am Zool 1999, 39:630-640.

166. Holland LZ: Evolution of new characters after whole genome duplications: insights from amphioxus. Sem Cell Dev Biol 2013, 24:101-109.

167. Capdevila J, Belmonte JCl: Patterning mechanisms controlling vertebrte limb development. Ann Rev Cell Dev Biol 2001, 17:87-132.

168. Röttinger $E$, Martindale MQ: Ventralization of an indirect developing hemichordate by $\mathrm{NiCl} 2$ suggests a conserved mechanism of dorsoventral (D/V) patterning in Ambulacraria (hemichordates and echinoderms). Dev Biol 2011, 354:173-190.

169. Range $R$, Angerer $R$, Angerer $L$ : Integration of canonical and noncanonical Wnt signaling pathways patterns the neuroectoderm along the anteriorposterior axis of sea urchin embryos. PLoS Biol 2013, 11:e1001467.

170. Emily-Fenouil F, Ghiglione C, Lhomond G, Lepage T, Gache C: GSK3beta/ shaggy mediates patterning along the animal-vegetal axis of the sea urchin embryo. Development 1998, 125:2489-2498.

171. Jeong J-Y, Einhorn Z, Mathur P, Chen L, Lee S, Kawakami K, Guo S: Patterning the zebrafish diencephalon by the conserved zinc-finger protein Fezl. Development 2007, 134:127-136.

172. Scholpp S, Foucher I, Staudt N, Peukert D, Lumsden A, Houart C: Otx1I, Otx2 and 1 rx $1 b$ establish and position the $\mathrm{ZLI}$ in the diencephalon. Development 2007, 134:3167-3176.

173. Martinez-Ferre A, Navarro-Garberi M, Bueno C, Martinez S: Wnt signal specifies the intrathalamic limit and its organizer properties by regulating Shh induction in the alar plate. J Neurosci 2013, 33:3967-3980.

174. Martinez-Ferre A, Martinez S: Molecular regionalization of the diencephalon. Front Neurosci 2012, 6:73

175. Puelles E, Annino A, Tuorto F, Usiello A, Acampora D, Czerny T, Brodski C, Ang S-L, Wurst W, Simeone A: Otx2 regulates the extent, identity and fate of neuronal progenitor domains in the ventral midbrain. Development 2004, 131:2037-2048.

176. Partanen J: FGF signalling pathways in development of the midbrain and anterior hindbrain. J Neurochem 2007, 101:1185-1193.

177. Kengaku M, Capdevila J, Rodriguez-Esteban C, De La Peña J, Johnson RL, Belmonte JCl, Tabin CJ: Distinct WNT pathways regulating AER formation and dorsoventral polarity in the chick limb bud. Science 1998, 280:1274-1277.

178. Tanaka M, Shigetani $Y$, Sugiyama S, Tamura K, Nakamura H, Ide H: Apical ectodermal ridge induction by the transplantation of En-1- 
overexpressing ectoderm in chick limb bud. Dev Growth Differ 1998 40:423-429.

179. Glardon S, Holland LZ, Gehring WJ, Holland ND: Isolation and developmental expression of the amphioxus Pax-6 gene (AmphiPax-6): insights into eye and photoreceptor evolution. Development 1998, 125:2701-2710.

180. Yu J-K, Satou Y, Holland ND, Shin-I T, Kohara Y, Satoh N, Bronner-Fraser M, Holland LZ: Axial patterning in cephalochordates and the evolution of the organizer. Nature 2007, 445:613-617.

181. Shimeld SM: The evolution of the hedgehog gene family in chordates: insights from amphioxus hedgehog. Dev Genes Evol 1999, 209:40-47.

182. Shimamura K, Rubenstein JL: Inductive interactions direct early regionalization of the mouse forebrain. Development 1997, 124:2709-2718

183. Imai KS, Stolfi A, Levine M, Satou Y: Gene regulatory networks underlying the compartmentalization of the Ciona central nervous system. Development 2009, 136:285-293.

184. Schubert M, Holland LZ, Panopoulou GD, Lehrach H, Holland ND: Characterization of amphioxus AmphiWnt8: insights into the evolution of patterning of the embryonic dorsoventral axis. Evol Dev 2000, 2:85-92.

185. Mazet F, Shimeld S: Characterisation of an amphioxus Fringe gene and the evolution of the vertebrate segmentation clock. Dev Genes Evol 2003, 213:505-509.

186. Holland LZ, Venkatesh TV, Gorlin A, Bodmer R, Holland ND: Characterization and developmental expression of AmphiNk2-2, an NK2 class homeobox gene from amphioxus (Phylum Chordata; Subphylum Cephalochordata). Dev Genes Evol 1998, 208:100-105.

187. Bertrand S, Camasses A, Somorjai I, Belgacem MR, Chabrol O, Escande M-L, Pontarotti $\mathrm{P}$, Escriva $\mathrm{H}$ : Amphioxus FGF signaling predicts the acquisition of vertebrate morphological traits. Proc Natl Acad Sci U S A 2011, 108:9160-9165.

188. Onai T, Lin H-C, Schubert M, Koop D, Osborne PW, Alvarez S, Alvarez R, Holland ND, Holland LZ: Retinoic acid and Wnt/ $\beta$-catenin have complementary roles in anterior/posterior patterning embryos of the basal chordate amphioxus. Dev Biol 2009, 332:223-233.

189. Hotta K, Takahashi H, Ueno N, Gojobori T: A genome-wide survey of the genes for planar polarity signaling or convergent extension-related genes in Ciona intestinalis and phylogenetic comparisons of evolutionary conserved signaling components. Gene 2003, 317:165-185.

190. Wagner E, Levine M: FGF signaling establishes the anterior border of the Ciona neural tube. Development 2012, 139:2351-2359.

191. Kozmik Z, Holland ND, Kalousova A, Paces J, Schubert M, Holland LZ: Characterization of an amphioxus paired box gene, AmphiPax2/5/8: developmental expression patterns in optic support cells, nephridium, thyroid-like structures and pharyngeal gill slits, but not in the midbrainhindbrain boundary region. Development 1999, 126:1295-1304.

192. Meulemans D, Bronner-Fraser M: The amphioxus SoxB family: implications for the evolution of vertebrate placodes. Int J Biol Sci 2007, 3:356-364.

193. Holland LZ, Kene M, Williams NA, Holland ND: Sequence and embryonic expression of the amphioxus engrailed gene (AmphiEn): the metameric pattern of transcription resembles that of its segment-polarity homolog in Drosophila. Development 1997, 124:1723-1732.

194. Ikuta T, Saiga H: Dynamic change in the expression of developmental genes in the ascidian central nervous system: revisit to the tripartite model and the origin of the midbrain-hindbrain boundary region. Dev Biol 2007, 312:631-643.

doi:10.1186/2041-9139-4-27

Cite this article as: Holland et al:: Evolution of bilaterian central nervous systems: a single origin? EvoDevo 2013 4:27.

\section{Submit your next manuscript to BioMed Central and take full advantage of:}

- Convenient online submission

- Thorough peer review

- No space constraints or color figure charges

- Immediate publication on acceptance

- Inclusion in PubMed, CAS, Scopus and Google Scholar

- Research which is freely available for redistribution

Submit your manuscript at www.biomedcentral.com/submit
C Biomed Central 